\title{
La huella ecológica, un indicador clave hacia la sostenibilidad territorial: el caso de España*
}

\author{
Ecological Footprint as a Key Territorial \\ Sustainability Indicator: A Case Study of Spain
}

\author{
Antonio Cano Orellana \\ Universidad de Sevilla
}

\section{Resumen}

Sin lugar a dudas, los seres humanos hemos sobrepasado los límites. Dicho de otro modo, en los primeros ocho meses de 2020, la humanidad ha consumido el presupuesto natural de todo el año. Disponer de información e indicadores que permitan determinar el impacto ecológico del comportamiento humano es un factor clave para afrontar la crisis ambiental y caminar hacia una sociedad sostenible. La huella ecológica, indicador sintético de sostenibilidad territorial, ha sido extensamente utilizada como herramienta útil para la gestión y planificación de la sostenibilidad, y se considera también un poderoso instrumento educativo para modificar los comportamientos de producción y consumo. En este artículo, tomando a España como referencia, nos centraremos en la pauta de localización seguida por la población española y su impacto ambiental, a través de la estimación de la huella ecológica generada por los 8.131 municipios españoles. Los resultados indican que la concentración de la población española, en una porción relativamente reducida de su territorio, principalmente en las grandes conurbaciones y el litoral, está estrechamente asociada a una huella ecológica que requiere del orden de 3,7 veces su superficie para satisfacer sus necesidades de producción y consumo.

Palabras clave: huella ecológica, sostenibilidad territorial, indicadores ecológicos, población, España.

Clasificación JEL: O50, Q56, Q57.

\section{Abstract}

No doubt human beings have exceeded the limits. In other words, in the first eight months of 2020 humanity has consumed the natural budget of the whole year. Having information and indicators that allow us to determine the ecological impact of human behaviour is a key factor in tackling the environmental crisis and moving towards a sustainable society. The ecological footprint, a synthetic indicator of territorial sustainability, has been widely used as a useful tool for sustainability management and planning, and is also considered a powerful educational tool for changing production and consumption behaviours. In this paper, taking Spain as a reference, we will focus on the location pattern followed by the Spanish population and its environmental impact, through the estimation of the ecological footprint generated by the 8.131 Spanish municipalities. The results indicate that the concentration of the Spanish population in a relatively small portion of its territory, mainly in the large conurbations and along the coast, is closely associated with an ecological footprint that requires on the order of 3.7 times its area to meet its production and consumption needs.

Keywords: ecological footprint, territorial sustainability, ecological indicators, population, Spain.

* El autor desea agradecer a Miguel Martínez-Almarza Cano, investigador en Network Mapping Group Knaresborough (North Yorkshire, UK), la elaboración de los mapas y su extraordinaria celeridad y paciencia. 


\section{Introducción}

El 22 de agosto de 2020 la humanidad agotó el presupuesto natural; esto es, en menos de nueve meses los seres humanos hemos consumido el presupuesto de todo el año (Global Footprint Network: https://www.footprintnetwork.org/our-work/ earth-overshoot-day/). A partir de este momento, el déficit ecológico se acumulará al anteriormente existente y las emisiones de carbono se incrementarán. El Día del Sobregiro de la Tierra (earth-overshoot-day) marca la fecha en que la demanda de recursos y servicios ecológicos excede, en un año determinado, lo que la Tierra puede regenerar durante ese mismo año. En España este límite se alcanzó el 27 de mayo de 2020 (https://www.overshootday.org/content/uploads/2020/02/GFN-Country-Overshoot-Day-2020.pdf). En otras palabras, vivimos muy por encima de los límites de la Naturaleza.

Desafortunadamente las advertencias, ya insistentemente planteadas en los años setenta y ochenta del pasado siglo, no han sido tenidas en cuenta. William Catton (1980) alertó, en su conocido Overshoot, que:

$\mathrm{Si}$, habiendo sobrepasado la capacidad de carga, no podemos evitar el colapso, tal vez con la comprensión ecológica de sus causas reales podamos seguir siendo humanos en circunstancias que de otra manera podrían tentarnos a convertirnos en bestias. Un mejor y más claro conocimiento -reclamabapodría evitar lamentaciones posteriores, permitiéndonos así abstenernos de infligirnos sufrimientos inútiles e imperdonables. (p. 216)

En este mismo sentido, para Lotka los seres humanos representamos una rueda insignificante en el engranaje de un great world engine (Lotka, 1925, p. 331). Una pieza minúscula, aunque poseedora de una enorme capacidad para alternar y condicionar el funcionamiento del planeta a través de la energía exosomática. Como Lotka (1945) describe con precisión:

En lugar de la lenta adaptación de la estructura anatómica y la función fisiológica en las generaciones sucesivas mediante la supervivencia selectiva, se ha logrado una mayor adaptación mediante el desarrollo incomparablemente más rápido de ayudas «artificiales» a nuestro aparato receptor-efector nativo, en un proceso que podría denominarse evolución exosomática. (p. 188)

En otros términos, la adición de los seres humanos a los instrumentos exosomáticos y su función bioeconómica, ha provocado un distanciamiento progresivo del comportamiento de otras especies vivas, que actúan más en sintonía con los límites biofísicos de la biosfera. Este alejamiento y la profundización en inciertas asimetrías, tal vez -como sugiriese Nicholas Georgescu-Roegen (1975) - muestren que:

Quizá el destino del hombre es tener una vida breve pero ardiente, excitante y extravagante, más bien que una existencia larga, apacible y vegetativa. 
Que sean otras especies, las amebas, por ejemplo, que no tienen ambiciones espirituales, las que hereden un planeta aún bañado en plenitud por la luz del sol. (p. 379)

Han sido suficientes las señales, se han prodigado los propósitos, pero el punto de no retorno está cada vez más cerca; así el necesario giro copernicano, por más que se anuncie y se reclame, muestra una tenaz resistencia. Por no remontarnos muy hacia atrás en el tiempo, tras la crisis financiera de finales de 2007 se habló de cuestionar el modelo de crecimiento actual, de las limitaciones que presentaba el PIB como indicador de bienestar (Stiglitz, Sen \& Fitoussi, 2010) e informar de la funcionalidad de los ecosistemas (Giannetti et al., 2015). En el escenario actual se persigue una revolución verde a través de un Green New Deal (Galvin \& Healy, 2020) o The European Green Deal (European Commission, 2019), un aterrizaje suave (Lovelock, 2007), el estado estacionario o el fin definitivo del crecimiento económico (Daly et al., 2019). Pero el tiempo se agota.

El propósito principal de este artículo es relacionar la pauta seguida por la población española en cuanto a su localización, y el impacto ambiental como una de sus consecuencias, estimado a partir de la huella ecológica de los 8.131 municipios españoles. El siguiente epígrafe presenta los propósitos iniciales de la herramienta propuesta por Wackernagel y Rees y su vinculación con el devenir de la sociedad urbano-industrial. A continuación, en el tercer epígrafe, se aborda el indicador de huella ecológica con algunos matices metodológicos importantes, a nuestro criterio, en el análisis territorial. Posteriormente, en el cuarto epígrafe, se describen las fuentes utilizadas y se presentan los resultados obtenidos, incorporando un epígrafe referido a la evolución de la población española, para el periodo comprendido entre 1960 y 2019 , relacionada con su localización en el territorio, así como una discusión de aquellos aspectos significativos que podrían ayudar a mejorar tanto el propio indicador de huella ecológica, como su interpretación. Por último, se extraen las principales conclusiones.

\section{La huella ecológica como indicador sintético de sostenibilidad territorial. La sociedad urbano-industrial y sus consecuencias}

La huella ecológica fue concebida desde sus orígenes como un indicador territorial de sostenibilidad (Rees, 1992, 1996; Wackernagel \& Rees, 1998). La creciente concentración urbana se entendía como el principal impulsor de la huella ecológica generada por los seres humanos. De hecho, como observaba en la Cumbre de Río de 1992 Maurice Strong: «la batalla por la sostenibilidad se ganará o perderá en las ciudades». Las ciudades se erigen como el principal atractor de recursos y el principal generador de desechos. El metabolismo urbano (Wolman, 1965) característico de la sociedad urbano-industrial ha transitado en, al menos, tres direcciones: a) concentración de la población en una porción cada vez más reducida del territorio; b) desarrollo a gran escala del transporte horizontal, alimentado con combustibles 
de origen fósil; $c$ ) metabolismo lineal, dejando los ciclos de materiales abiertos, muy exigente en recursos naturales e importante generador de desechos, provocando, como consecuencia de ello, una escasez social de recursos naturales y una extraordinaria acumulación de desechos. Los requerimientos de recursos derivados de este metabolismo presentan un problema adicional, y este no es otro que considerar como hábitat humano el conjunto del planeta. Este hecho rompe la relación existente entre las localizaciones ecológicas y geográficas, característica del resto de especies vivas. Una parte importante de la población humana, la más exigente en cuanto a generación de huella ecológica, no obtiene los recursos ni vierte los desechos allí donde habita. La actividad extractiva y de generación de desechos, estrechamente vinculada a la capacidad de carga apropiada y a la huella ecológica generada, además no está homogéneamente repartida. Poco más del $16 \%$ de la población mundial concentra aproximadamente el $80 \%$ de los recursos extraídos y producidos, así como un porcentaje similar de los desechos generados.

Lo antes descrito se vuelve particularmente revelador cuando tratamos de comparar los requerimientos humanos, de realidades territoriales específicas, o de la población humana en general, con el área ecológica necesaria para la producción de comida, absorción de desechos, etcétera. En ecología, el tamaño máximo de población de una determinada especie que un hábitat definido puede sustentar indefinidamente, sin menoscabo del ecosistema del que depende, se denomina «capacidad de carga» (Common \& Stagl, 2008, p. 45).

Esta definición, no obstante, no parece aplicable a los seres humanos dada su aparente facultad para aumentar, casi ilimitadamente, la «capacidad de carga humana» (Kessler, 1994). En su pretensión por someter a la naturaleza, para fines exclusivamente humanos, elimina especies competidoras, se apropia de tecnologías vernáculas, extrae recursos localmente escasos, y extiende, cuanto le sea posible, la «evolución exosomática» ${ }^{1}$ (Lotka, 1945 , p. 188) a través de la tecnología y el conocimiento.

La evolución exosomática causó -siguiendo a Georgescu-Roegen (1975, p. 815)dos cambios fundamentales e irrevocables en la especie humana. De un lado, el irreductible conflicto social característico de ella, al que son ajenas otras especies que viven en sociedad, dado que las divisiones existentes entre ellas están biológicamente marcadas (como es, por ejemplo, el caso de las abejas). De otro, la adición de los seres humanos a los artefactos exosomáticos. Fruto de esta adición la supervivencia de la especie humana se enfrenta a problemas tanto de naturaleza biológica como económica; esto es, son de índole bioeconómica.

En este sentido, la terminología propuesta por Lotka subraya el hecho de que «el proceso económico es una continuación del biológico» (Georgescu-Roegen, 1996, p. 381).

1 Para Lotka, los factores exosomáticos son diferentes de los órganos genéticos y endosomáticos (con los que cada individuo nace, como piernas, cabeza, manos, garras, alas, etcétera). Los factores exosomáticos son tanto las herramientas como los dispositivos utilizados por las personas para producir, intercambiar y consumir. 
De hecho, no solo es continuación uno del otro, sino que, además, ambos son complementarios (Daly, 1999, pp. 19-20). Es más, en el camino hacia la sostenibilidad global:

[...] tenemos que dejar de pensar que los objetivos de la ecología y la economía están en conflicto. Los sistemas económicos dependen de los sistemas ecológicos de sustentación de la vida, y tenemos que darnos cuenta de ese hecho e incorporarlo en nuestro modo de pensar y en nuestras actuaciones a nivel realmente básico, si es que queremos mantener nuestra economía global. No es posible que subsista una casa cuyos miembros están divididos y enfrentados. (Constanza, 1997, p. 103)

Lo relevante aquí es que la capacidad de carga biofísica o ecológica, en concreto, en el contexto de este artículo, está considerablemente relacionada con la carga cultural. De este modo, atendiendo al singular comportamiento humano, Catton Jr.(2009) define la capacidad de carga como «la máxima carga que un hábitat puede soportar indefinidamente»; esto es, «la máxima carga humana sostenible» (p. 133). La palabra clave es «carga» o presión soportada por el medio. De ahí que el énfasis no se ha de poner tanto en el número de individuos, sino, más bien, en la capacidad de los ecosistemas de seguir, de forma sostenida en el tiempo, suministrando recursos y prestando funciones ambientales. El problema, como el mismo observa, consiste en que:

Se está exigiendo al mundo que acoja no sólo a más personas, sino también a personas ciertamente «grandes», cuya ansia de recursos y poder, que degradan el planeta que nos sustenta, se ha visto acrecentada por la tecnología [...]. La cuestión de la capacidad de carga humana, pues, parece mucho más urgente cuando pensamos en términos de «presión de la carga» sobre los ecosistemas terrestres, en lugar de contemplar la mera «presión de la población». (Catton Jr., 2009, p. 128)

Catton, al tratar este asunto, sugiere que, referida a la especie humana, el concepto de sobrepoblación, así como la de capacidad de carga, requiere un tratamiento específico. En concreto, sugiere invertir los términos en la ratio utilizada para determinar la capacidad de carga. Esto es, situar en el numerador no la máxima población que un hábitat puede sostener, sino la carga máxima que este puede soportar.

Esta idea sugerida inicialmente por Catton (1986), fue el punto de partida de la noción de huella ecológica:

[...] una cuestión fundamental para la economía ecológica es si los suministros de capital natural serán adecuados para satisfacer la demanda prevista para el próximo siglo. Invertir la relación estándar de capacidad de carga sugiere una manera poderosa de abordar esta cuestión crítica. En lugar de preguntarse qué población puede sostener una región determinada de manera 
sostenible, se plantea la cuestión de la capacidad de sustentación: ¿cuán grande es la superficie de tierra productiva que se necesita para sostener indefinidamente una población específica, con independencia de su localización en cualquier lugar de la Tierra? (Rees, 1996, p. 203)

De manera formalizada, la huella ecológica de una población o economía específica puede definirse como el área de tierra (y agua) ecológicamente productiva de varias clases -cultivos, pastos, bosques, etc.- que se requeriría de manera continua para: $a$ ) proporcionar todos los recursos energéticos/materiales consumidos, y b) absorber todos los desechos generados por esa población con la tecnología predominante, en cualquier lugar de la Tierra dondequiera que se localice el área ecológicamente productiva requerida (Wackernagel \& Rees, 1998, pp. 51-52).

En realidad, la huella ecológica no es más que la «capacidad de carga apropiada» (Rees \& Wackernagel, 1994) por los seres humanos para satisfacer su proceso metabólico.

Desde que se formalizó su creación ha ido creciendo el interés por el análisis de la huella ecológica, principalmente para mejorar la comprensión de los límites biofísicos existentes en la biosfera para satisfacer las demandas humanas de capital natural. Dicho de otro modo, las herramientas conceptuales y los indicadores al uso, especialmente los utilizados en el análisis económico, tales como el PIB o la Renta Nacional, han mostrado su incapacidad para informar adecuadamente sobre el bienestar de las sociedades humanas y, especialmente relevante en el contexto de este artículo, para advertir si estas se orientan o no en el sentido de la sostenibilidad. Esto es, si la especie humana no ha ido, en cuanto a sus exigencias, más allá de la capacidad de su entorno para sostenerla, no ha sobrepasado los límites.

La construcción de la sociedad actual indudablemente ha traído consigo importantes mejoras para la población. Sectores importantes de ella han podido acceder tanto a bienes materiales como inmateriales impensables en las sociedades anteriores. Pero, al mismo tiempo, la manera en que hemos diseñado el mundo que conocemos tiene un coste nada despreciable.

Hemos incurrido en errores importantes de diseño (McDonough \& Braungart, 2005). No solo en el diseño de los materiales producidos sino también, y esto en el contexto de este trabajo adquiere singular relevancia, en el diseño de la propia sociedad que ha impulsado unas pautas de producción y consumo económica, social y ambientalmente insostenibles. La concentración de la población en grandes ciudades y enclaves frágiles del territorio, el trasiego permanente de mercancías y el abuso de fuentes energéticas de origen fósil están en la base de este diseño. Según Naciones Unidas (en adelante NN. UU.), en 2018, casi el 55\% de las personas en el mundo habitaba en ciudades. La población urbana en el mundo en 1950 era de 751 millones ( $29,8 \%$ del total), en 2018 se elevaba a 4.195 millones (54,3\%), el continente asiático albergaba el $54 \%$ de la población urbana mundial (Naciones Unidas, 2018). Doce mil seiscientos millones de toneladas se transportaron en el mundo en 2017. Cada tonelada exportada recorrió, en este mismo año, $5.214,9 \mathrm{~km}$, y cada tonelada importada tuvo que recorrer 5.069,7 km (Chatham House, 2018). Las fuentes ener- 
géticas que, en la actualidad, alimentan un modelo como el descrito son básicamente de origen fósil. En 2019, el 84,3\% de la demanda mundial de energía primaria consumida era de origen fósil (BP, 2020), el transporte por carretera consumió más del $40 \%$ de toda la demanda de petróleo en 2019 (BloombergNEF, 2020). En términos de huella ecológica, del $\mathrm{CO}_{2}$ emitido en $2015,8,8 \mathrm{Gt}$, que representan el 27,2\% de las emisiones mundiales de $\mathrm{CO}_{2}$ procedente de la quema de combustibles de origen fósil, está vinculado al comercio internacional (OECD, 2020).

\section{La huella ecológica. Apuntes metodológicos}

Como indicador territorial de sostenibilidad, la huella ecológica fija su atención en el territorio. Los enclaves urbanos, con su exigente metabolismo, son necesariamente una referencia imprescindible.

En la perspectiva de una sociedad sostenible, donde el análisis de la huella ecológica adquiere relevancia, un indicador muy importante lo constituye el patrón de consumo.

De hecho, la huella ecológica traduce a hectáreas globales ${ }^{2}$ (hag) el consumo aparente. Esto es la Ecuación [1]:

$$
C A=P+M-X
$$

Discrimina, por tanto, en su contabilidad, a la población en función de su capacidad de consumir, tanto cuantitativa como cualitativamente. Es decir, su cálculo tiene en cuenta tanto la cantidad consumida como el tipo de consumo que ha tenido lugar. Para ello, divide las hectáreas globales en cinco categorías: 1) superficie agrícola; 2) pastizales; 3) superficie construida, infraestructuras; 4) pesquerías, y 5) superficie forestal.

La huella ecológica se calcula de acuerdo con el agregado siguiente ${ }^{3}$ (Ecuación [2]):

$$
H E_{P}=\sum_{i} \frac{P_{i}}{R_{N, i}} \cdot F R_{N, i} \cdot F E_{N, i}=\sum_{i} \frac{P_{i}}{R_{M, i}} \cdot F E_{N, i}
$$

2 Una hectárea global es una hectárea biológicamente productiva con una productividad biológica media mundial para un año determinado. Las hectáreas globales son necesarias porque los diferentes tipos de superficies de la tierra tienen productividades distintas. La hectárea global es el criterio utilizado en la contabilidad de la huella ecológica.

${ }^{3}$ La huella ecológica tiene dos características (Wackernagel et al., 2019): 1) Aditividad: dado que la vida humana compite por las superficies biológicamente productivas, estas superficies pueden sumarse. La huella ecológica suma todas las demandas humanas sobre la naturaleza que compiten por el espacio biológicamente productivo. Esto significa que estos espacios se excluyen mutuamente al proporcionar recursos biológicos, acomodar la infraestructura urbana o absorber el exceso de carbono de la quema de combustibles fósiles. Permitiendo, además, que la superficie que satisface las demandas humanas (huella ecológica) pueda compararse con el espacio biológicamente productivo disponible (biocapacidad). 2) Equivalencia (factor de ponderación o escala): como no todas las superficies biológicamente productivas tienen la misma productividad, las áreas se ponderan proporcionalmente a su productividad biológica. Por tanto, la unidad de medida para la contabilidad de la huella ecológica, las hectáreas globales, son las consideradas biológicamente productivas con una productividad media mundial; esto es, sería la misma cada año, puesto que variará de un año a otro, para todos los países. 
Donde $P$ es la cantidad de cada producto $i$ extraído (o dióxido de carbono emitido) en cada nación o área territorial específica; $R_{N}$ es el rendimiento medio anual, nacional o regional, por hectárea de producción del producto $i$ (o su capacidad de absorción de carbono en los casos en que $P$ es el $\mathrm{CO}_{2}$ generado); $F R_{N, i}$ es el factor de rendimiento específico, para cada nación o región, para la producción de cada producto $i ; R_{M, i}$ es el rendimiento medio mundial del producto $i$; y, por último, $F E_{N, i}$ es el factor de equivalencia para cada tipo de área de producción del producto $i$.

En el Cuadro 1 se muestran los factores de rendimiento para el último año estimado, esto es, para 2017.

\section{CUADRO 1}

FACTORES DE RENDIMIENTO (2017)

\begin{tabular}{|l|c|}
\hline \multicolumn{1}{|c|}{$\begin{array}{c}\text { Tipo de uso de } \\
\text { la tierra }\end{array}$} & $\begin{array}{c}\text { Factor de rendimiento } \\
\text { (hag) }\end{array}$ \\
\hline Agrícola & 0,59 \\
\hline Pastizales & 1,21 \\
\hline Forestal & 0,84 \\
\hline Pesquerías & 1,00 \\
\hline Infraestructuras & 0,59 \\
\hline
\end{tabular}

FUENTE: Global Footprint Network, 2021.

La equivalencia entre el segundo y tercer término de la Ecuación [1] se debe a la relación:

$$
F R_{N, i}=\frac{R_{N, i}}{R_{M, i}}
$$

Los factores de equivalencia, así como los factores de rendimientos antes indicados, se introducen en la estimación de la huella ecológica con el fin de evaluar la productividad biológica de los distintos tipos de superficies y sus usos. Cada categoría de superficie (agrícola, pastizal, forestal, pesquería e infraestructura) tienen productividades biológicas diferentes. Por tanto, antes de sumarlas es necesario normalizarlas. Esto no solamente ayuda a comparar entre diversas superficies biológicamente productivas, sino que, además, permiten una comparación entre las estimaciones de huella ecológica realizada para distintos territorios. Los factores de equivalencia y rendimiento son, por tanto, factores de ponderación o escala, que permiten homogeneizar los distintos usos antes de agregarlos, y obtener de ese modo la huella ecológica y la biocapacidad total expresadas en lo que se denomina «hectáreas globales». La hectárea global, pues, no es más que la relación entre la productividad media mundial de cada categoría de superficie respecto al promedio de la productividad mundial de todos los tipos de tierra biológicamente productivos; que varía según el tipo o categoría de tierra y año. 
Aunque los factores de equivalencia son difíciles de medir, dado que estas mediciones parten de asumir determinados supuestos y de estimaciones indirectas, pueden, no obstante, tener un soporte empírico (Wackernagel et al., 2014). Siempre que exista información disponible estos pueden estimarse, por ejemplo, a partir de la producción primaria neta o de la emergía ${ }^{4}$ (Yang et al., 2018; Galli et al., 2020).

En este artículo se tomó la serie de la huella ecológica para España, las más larga existente en la actualidad, de Global Footprint Network (2021) factores de equivalencia a partir de los índices de idoneidad del modelo de Zonas Agroecológicas Mundiales (GAEZ, por sus siglas en inglés), combinados con la información sobre las áreas reales de cultivo, bosque y pastoreo de FAOSTAT (Zonas Agroecológicas Mundiales 2000; Base de Datos Estadísticos ResourceSTAT de la FAO). El modelo GAEZ divide todas las tierras a nivel mundial en cinco categorías, a cada una de las cuales se le asigna una puntuación de idoneidad (Cuadro 2).

\footnotetext{
${ }^{4}$ Ambos conceptos, producción primaria neta (PPN) y emergía (Em), están de algún modo relacionados con la energía. De hecho, la producción en los ecosistemas implica la fijación y transferencia de energía proveniente del sol, a través de los ecosistemas, gobernada por las leyes de la termodinámica. La tasa a la cual las plantas producen tejido vegetal se conoce como productividad primaria. La productividad primaria bruta (PPB) es la cantidad total de energía solar que absorben las plantas mediante la fotosíntesis, mientras que la productividad primaria neta (PPN) es esa productividad menos la cantidad de energía liberada al medioambiente a través de la respiración; es decir, la cantidad de energía que, efectivamente, se almacena en el tejido vegetal. La PPN es, por tanto, la cantidad de energía potencialmente disponible para los animales que se alimentan de plantas (Common \& Stagl, 2008, p. 83). Con el transcurso del tiempo la PPN se acumula como masa vegetal. Dicha biomasa se expresa habitualmente como gramos de materia orgánica por metros cuadrado $\left(\mathrm{g} / \mathrm{m}^{2}\right)$, o como calorías por metro cuadrado $\left(\mathrm{cal} / \mathrm{m}^{2}\right)$. Obsérvese que biomasa y productividad son conceptos diferentes. La biomasa es la cantidad de materia orgánica existente en un momento concreto. En cambio, la productividad es la tasa a la cual la materia orgánica se genera por medio de la fotosíntesis.

La emergía, por su parte, es la energía disponible (exergía), de un determinado tipo, que se ha usado directa o indirectamente en las transformaciones necesarias para generar un producto o servicio (Odum, 1996). La idea original del concepto, que más tarde se acuñaría con el término emergía (Scienceman, 1987), la sugiere Odum (1973, p. 224) de la forma siguiente: «La energía se mide por calorías, BTU, kilovatios hora y otras unidades equivalentes, pero la escala de calidad de la energía no se indica en estas medidas. La capacidad de generar trabajo, para las personas, depende de la calidad y cantidad de energía, y esto se mide a través de la cantidad de energía requerida de un grado de calidad inferior para desarrollar un grado de calidad superior. La escala de energía va desde la luz solar diluida hasta la materia vegetal, de ahí al carbón, desde el carbón al petróleo, a la electricidad y hasta los esfuerzos de alta calidad del procesamiento de la información de las computadoras y del propio ser humano». En cierto modo, informa del flujo energético que tiene lugar a lo largo de todo el proceso del ciclo de vida de un producto o servicio, su «memoria energética» (Scienceman, 1987). Cada una de estas formas de energía, se produce a través de procesos de transformación en la naturaleza y tiene una determinada capacidad para realizar trabajo, tanto en sistemas ecológicos como humanos. La emergía tiene en cuenta, y efectivamente cuantifica, la calidad de las diferentes formas de energía. El reconocimiento de esas diferencias en calidad, es un concepto clave en la metodología de la emergía. Su unidad es el emjulio energético. Existe un tipo de emergía diferente para cada tipo de energía disponible. Por ejemplo, la emergía solar se expresa en emjulios solares (en su forma abreviada, sej), la emergía del carbón en emjulios de carbón y la emergía eléctrica en emjulios eléctricos. No hay, en cambio, emergía en la energía degradada (energía sin disponibilidad para realizar trabajo). Del mismo modo que la energía, la emergía se mide en relación con un nivel de referencia. En la mayoría de las aplicaciones se utilizan las unidades de emergía solar.

${ }^{5}$ Adicionalmente, la ventaja de utilizar esta fuente es que permite la comparación entre países, dado que las estimaciones para el conjunto de países del resto del mundo utiliza la misma metodología, y, en consecuencia, los mismos factores de equivalencia.
} 


\section{CUADRO 2 \\ PUNTUACIÓN DE IDONEIDAD}

\begin{tabular}{|l|c|}
\hline \multicolumn{1}{|c|}{ Idoneidad } & Puntuación \\
\hline Muy adecuado (VS, sus siglas en inglés) & 0,9 \\
\hline Adecuado (S, su sigla en inglés) & 0,7 \\
\hline Moderadamente adecuado (MS, sus siglas en inglés) & 0,5 \\
\hline Marginalmente adecuado (mS, sus siglas en inglés) & 0,3 \\
\hline No apto (NS, sus siglas en inglés) & 0,1 \\
\hline
\end{tabular}

FUENTE: Lin et al., 2019.

\section{GRÁFICO 1}

\section{PUNTUACIONES DE IDONEIDAD Y USOS DEL SUELO}

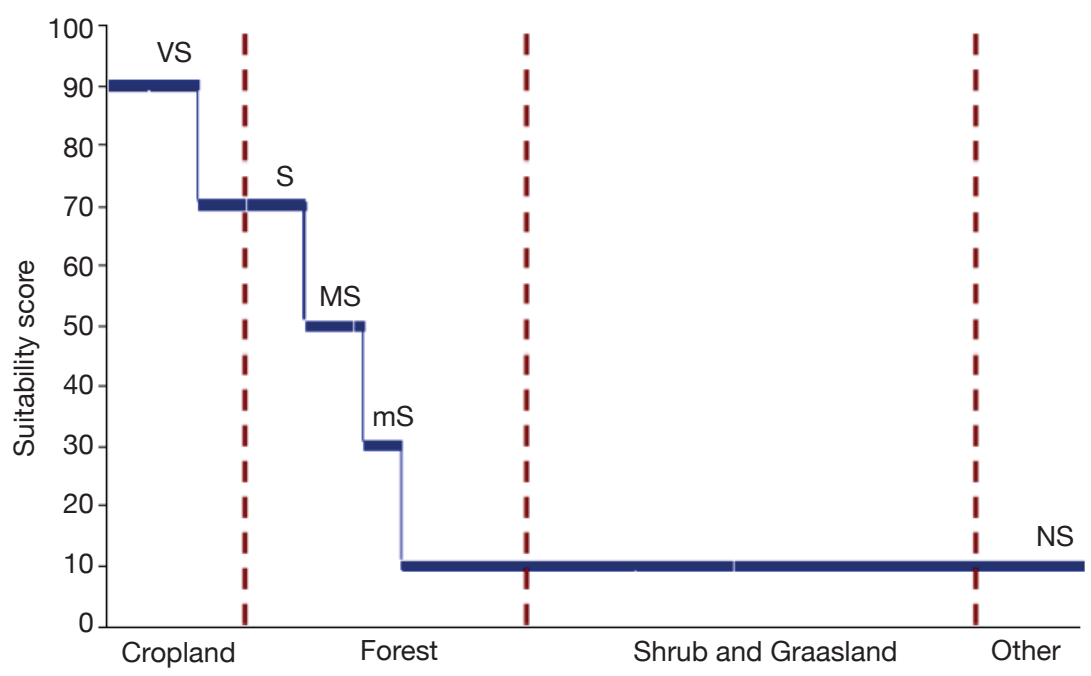

NOTA: El número total de hectáreas de superficie bioproductiva se muestra, mediante su longitud, en el eje horizontal (abscisas). Las líneas verticales discontinuas dividen la superficie total en los tres tipos de uso de la tierra terrestre para los que se calculan los factores de equivalencia (tierras de cultivo, bosques y pastizales). La longitud de cada barra horizontal del gráfico muestra la cantidad total de tierra disponible con cada índice de idoneidad. La ubicación vertical (eje de ordenadas) de cada barra refleja la puntuación de idoneidad para ese índice de idoneidad, entre 10 y 90 .

FUENTE: Ewing et al., 2010.

El Gráfico 1 representa la relación entre las puntuaciones de idoneidad de las zonas agroecológicas mundiales (GAEZ) -basada en el Marco de Evaluación de Tierras que utiliza la FAO desde 1978- con los tipos de suelo utilizados en las Cuentas Nacionales de huella ecológica y biocapacidad. 
El cálculo del factor de equivalencia supone que las tierras más productivas se destinan a su uso más productivo. Los cálculos parten de la base de que la tierra más adecuada disponible se dedicará a la agricultura, la siguiente tierra más adecuada será la forestal y la menos adecuada será la de pastoreo. El factor de equivalencia se calcula como la relación entre el índice de idoneidad medio de un tipo de uso del suelo determinado dividido por el índice de idoneidad medio de todos los tipos de uso del suelo.

El Cuadro 3 ilustra la traducción de la escala anterior asociados a los distintos usos de la tierra considerados en el cálculo de la huella ecológica, para el año 2017.

\section{CUADRO 3}

FACTORES DE EQUIVALENCIA (2017)

\begin{tabular}{|l|c|}
\hline \multicolumn{1}{|c|}{ Tipo de uso de la tierra } & Factor de equivalencia (hag) \\
\hline Agrícola & 2,49 \\
\hline Pastizales & 0,46 \\
\hline Forestal & 1,28 \\
\hline Pesquerías & 0,37 \\
\hline Infraestructuras & 2,49 \\
\hline
\end{tabular}

FUENTE: Global Footprint Network, 2021.

Obsérvese que el factor de equivalencia, como ocurre con el factor de rendimiento, para las zonas edificadas es igual al factor de equivalencia para las tierras de cultivo. Se asume, por tanto, que las zonas edificadas ocupan antiguas tierras de cultivo; basándose en el hecho de que los asentamientos humanos se han desarrollado y congregado históricamente en las tierras más fértiles desde el punto de vista agrícola. Este supuesto sobreestima tanto la huella como la biocapacidad de las superficies artificializadas situadas en áreas tradicionalmente de baja productividad. Sin embargo, como la huella y la biocapacidad de las tierras construidas son iguales, cualquier sesgo en esta suposición afectará por igual tanto a una como a otra. Los países áridos, en particular, pueden estar sujetos a una sobreestimación sistemática de su huella y biocapacidad de las zonas edificadas.

En cuanto al factor de equivalencia para la superficie marina se calcula de forma que una hectárea global de pastos produzca una cantidad de calorías de carne de vacuno igual a la cantidad de calorías de salmón que puede producirse en una hectárea global de superficie marina. El factor de equivalencia para las aguas continentales se establece igual al factor de equivalencia para la superficie marina.

El procedimiento antes descrito, generalmente utilizado para el cálculo de la huella ecológica de las naciones, de acuerdo con la metodología desarrollada por la Global Footprint Network puede aplicarse, por analogía, a niveles territoriales de menor escala que la nación (regionales, provinciales, locales...). 


\section{Resultados y discusión}

\subsection{Distribución territorial de la población española}

En ecología y geografía se entiende por antropización la conversión de espacios abiertos, paisajes y entornos naturales debidos a la acción humana. La erosión antropogénica, por consiguiente, es el proceso de alteración, en muchos casos degradación, del terreno y del suelo provocado por la intervención humana. Si a esto unimos que los seres humanos, en sus ansias de recursos, son -como afirma Catton (1986)ciertamente grandes, y que concibe el planeta en su totalidad como su hábitat, el factor demográfico es absolutamente relevante en el análisis de la huella ecológica.

La irregular distribución de la población humana en el territorio, así como la transformación en los usos del suelo, es ajena, generalmente, a las limitaciones de los ecosistemas que ocupan. La tecnología y las prácticas de gestión de los recursos naturales, así como el tratamiento de los desechos, puede modificar la capacidad de carga que soportan los ecosistemas. Pero, en la mayoría de los casos se ve alterada negativamente debido a las presiones ejercidas por las pautas de localización, producción y consumo de la población.

El cambio de uso del suelo destinado a uso urbano supone uno de los impactos humanos más irreversibles sobre los ecosistemas planetarios. En general, ocupa tierras fértiles, provoca alteraciones en los ciclos hidrológicos, biogeoquímicos, afecta al clima local, fragmenta los hábitats y suponen una seria amenaza para la biodiversidad. Utilizando imágenes de teledetección para cartografiar la conversión del suelo urbano, entre 1970 y 2000 , en todas las regiones del mundo, las tasas de expansión del suelo urbano fueron superiores o iguales a las tasas de crecimiento de la población urbana, lo que sugiere que el crecimiento urbano fue más expansivo que compacto (Seto et al., 2011).

El crecimiento urbano actual y futuro, si se mantienen la dinámica observada en las últimas décadas, afectará probablemente a la mayoría de las zonas biológicamente diversas y sensibles, como bosques, sabanas, cuencas de los grandes ríos y el litoral.

El comportamiento de la población española y su localización en el territorio no ha sido ajeno a estas dinámicas. La localización de la población española ha tendido a concentrarse en torno a las grandes ciudades, conurbaciones en la actualidad, y en las ciudades costeras. Este comportamiento, muchas veces favorecido más por un efecto expulsión que atracción, ha ido creciendo con el transcurso del tiempo y se mantiene en la actualidad. Hecho que guarda relación con un vaciamiento progresivo de determinadas áreas del territorio y un desplazamiento de la población hacia una porción de superficie cada vez más reducida.

En 1900, la población española era de 18.830 .649 personas, en 2019 se había multiplicado por 2,5 veces, hasta las 47.013 .472 personas. El Cuadro 4 muestra la evolución de la población. Como puede observarse, entre 1900 y 1960 un $46 \%$ 


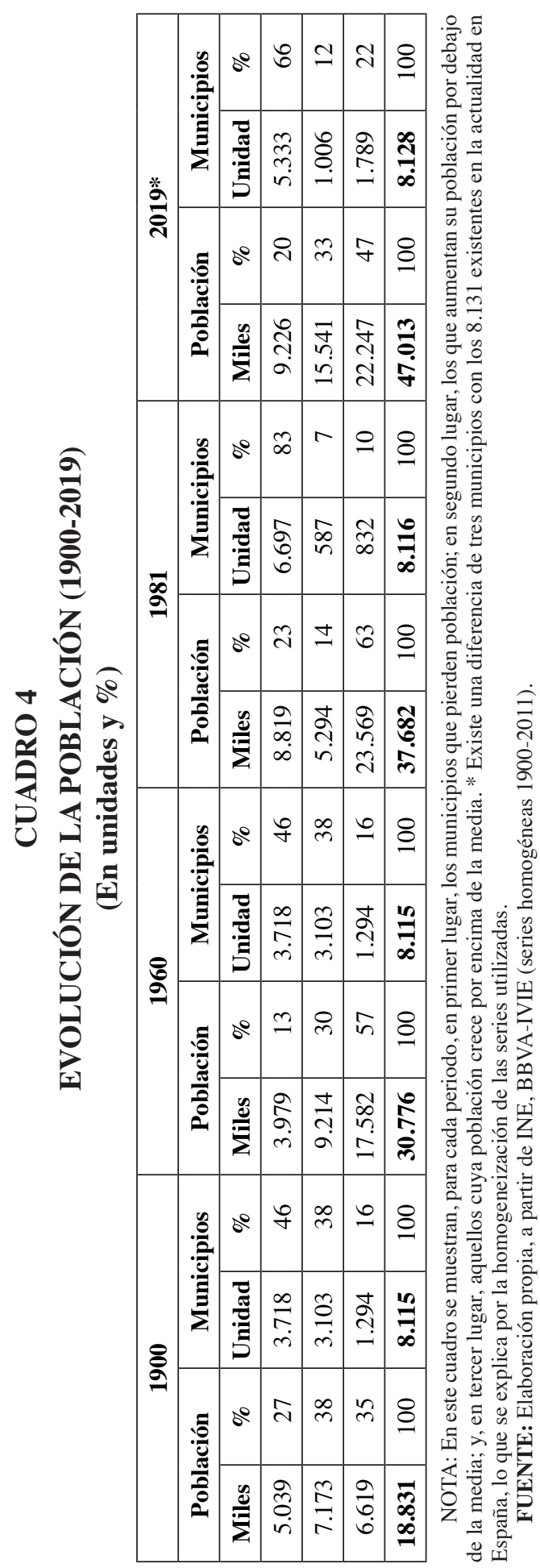


de los municipios españoles pierde población. En el periodo posterior analizado, entre 1960 y 1980, algo más del $82 \%$ de los municipios sigue perdiendo población. Situación esta que se repite en el último periodo considerado, entre 1981 y 2109, en el cual casi dos tercios de los municipios españoles siguen perdiendo población.

La localización puede apreciarse mejor a través de las densidades de población y su localización (Mapa 1).

En 2019, el 50,06\% de la población, correspondiente a 123 municipios de los 3.131 existentes, el 3,9\% del total, habitaba en tan solo el 4,8\% del territorio. El $20 \%$ de la población; en cambio, 7.364 municipios se localizaban en el 80,57\% de la superficie total.

\section{MAPA 1}

DENSIDAD DE LOS MUNICIPIOS ESPAÑOLES (2019)

(En hab./km²)

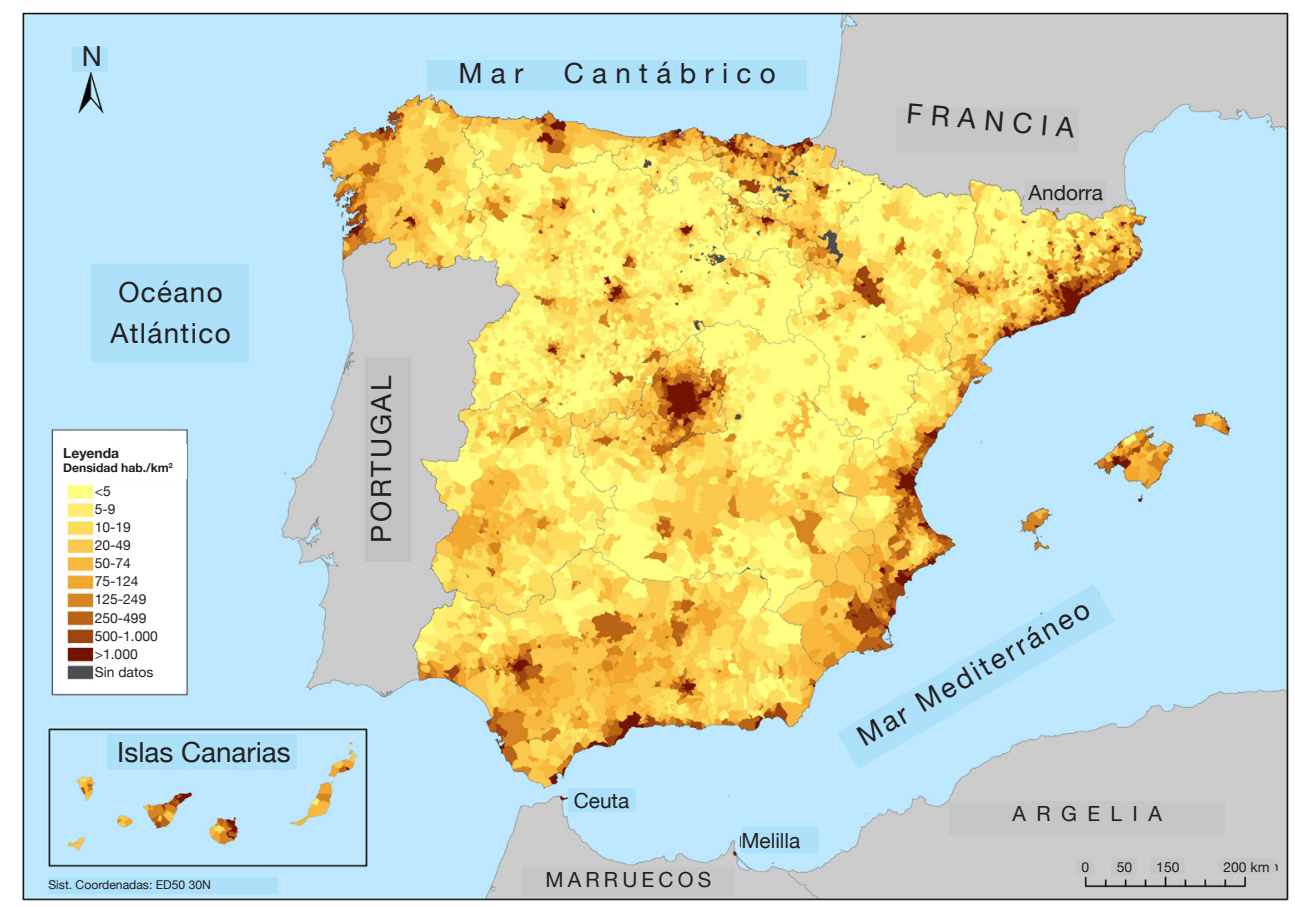

NOTA: El software utilizado para la construcción de los mapas ha sido ArcGIS 10.5.

FUENTE: Elaboración propia, a partir IGN. 


\subsection{La huella ecológica de España. Una aproximación a la estimación para los municipios españoles}

La información referida a la huella ecológica de España, utilizada en este artículo, procede de la edición de 2021 de las Cuentas Nacionales de Huella Ecológica y Biocapacidad de Global Footprint Network. La serie construida, que va de 1961 a 2017, se basa en un conjunto de datos tomados de NN. UU. Estiman, año a año, la cantidad de recursos que usamos (huella ecológica) y la cantidad de la que disponemos (biocapacidad). Los resultados de estas estimaciones muestran el impacto ecológico de un país determinado. Este tendrá una reserva ecológica si su huella ecológica es menor que su biocapacidad; en caso contrario, incurrirá en un déficit ecológico. A los primeros se les suele denominar acreedores ecológicos, y a los segundos deudores ecológicos (Mapas 2a y 2b).

\section{MAPA 2a}

ACREEDORES Y DEUDORES ECOLÓGICOS (2017)

ACREEDORES

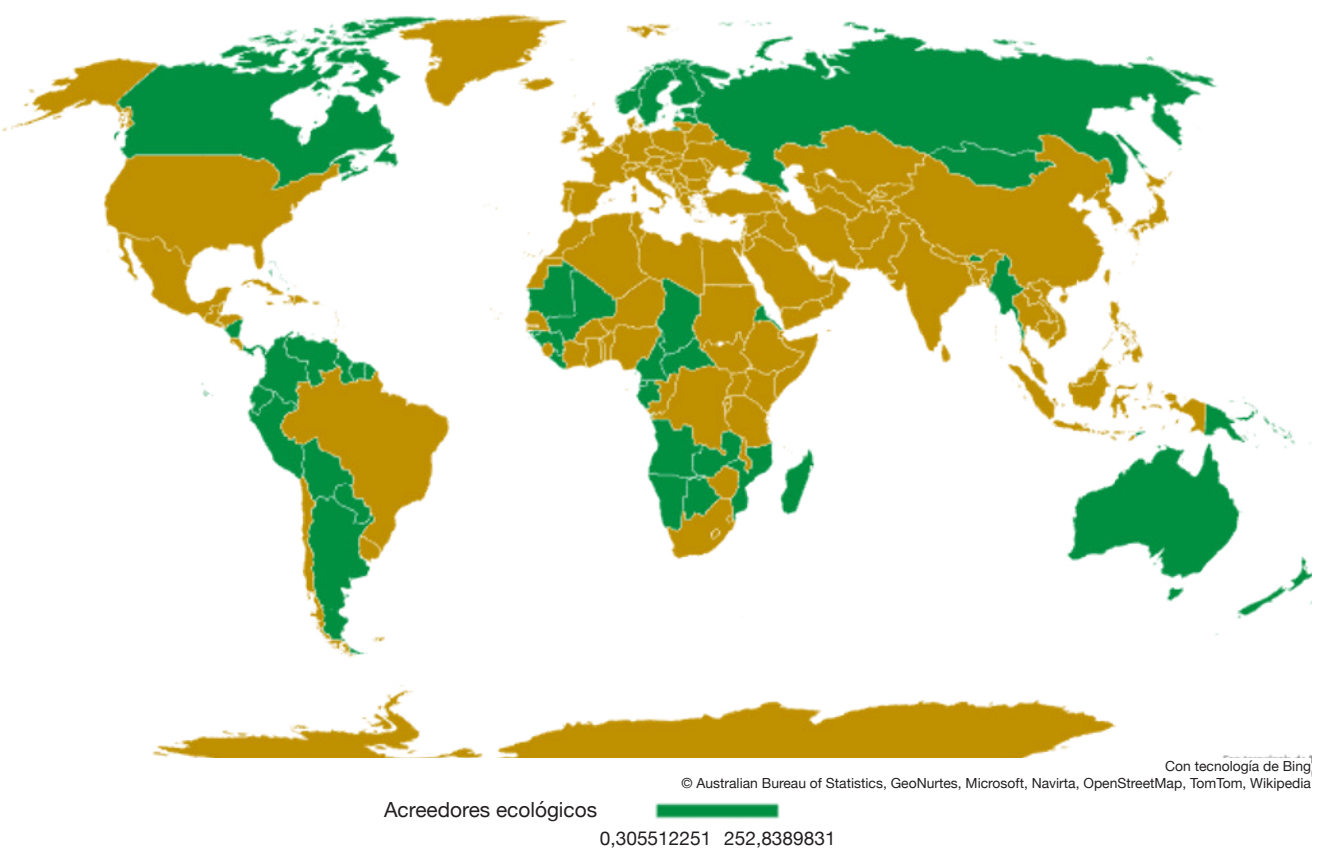

FUENTE: Elaboración propia, a partir de Global Footprint Network. 


\section{MAPA 2b}

\section{ACREEDORES Y DEUDORES ECOLÓGICOS (2017)}

DEUDORES

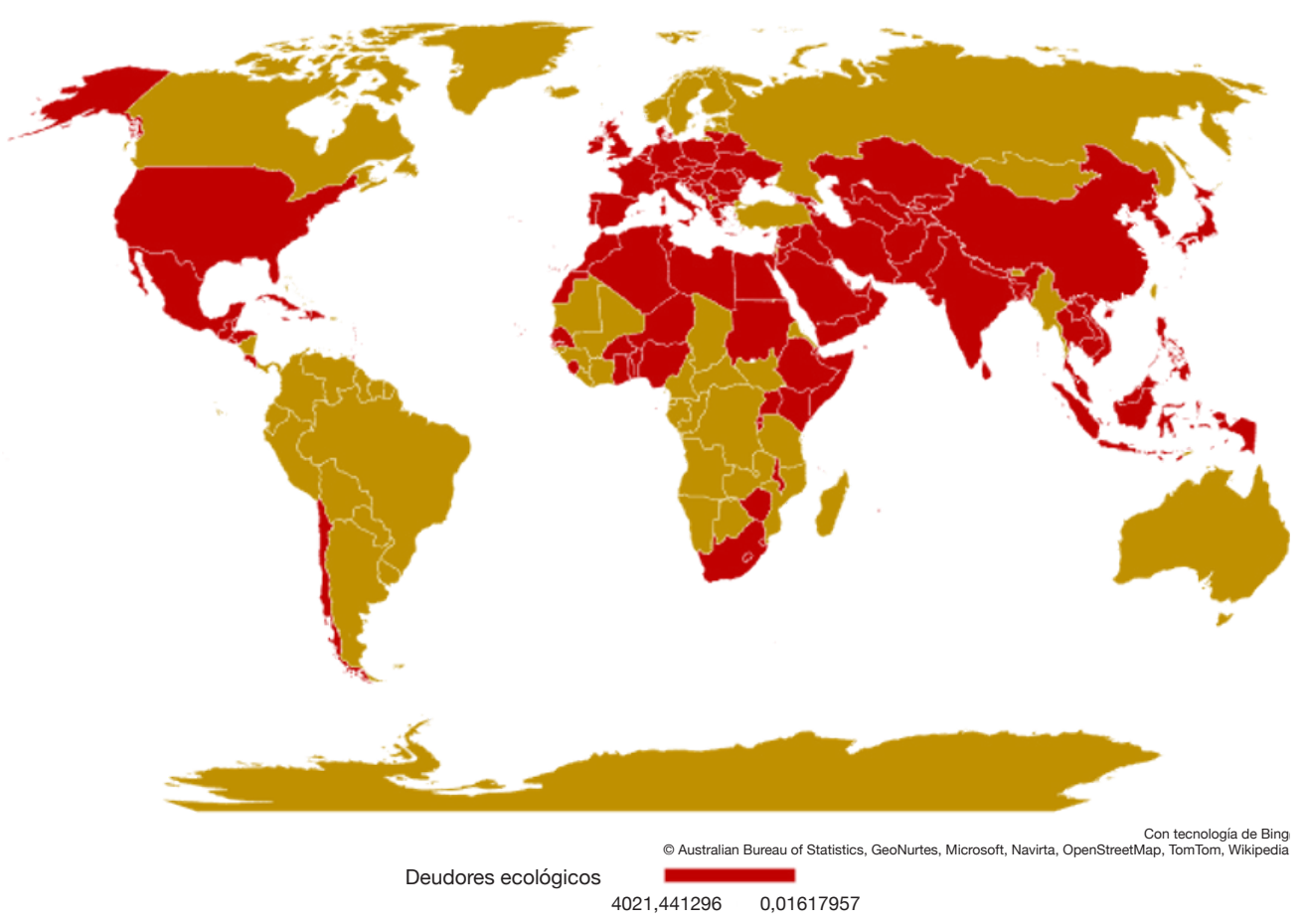

FUENTE: Elaboración propia, a partir de Global Footprint Network.

Tanto la demanda como la disponibilidad se expresan en las denominadas hectáreas globales, que, como se ha indicado antes, no son más que las hectáreas ajustadas a la productividad, mundial y local, con el propósito de hacer que los datos sean comparables a escala mundial. La contabilidad biofísica utilizada en el análisis de la huella ecológica incorpora variables socioeconómicas de los países. Esto permite contrastar los resultados obtenidos con una posterior evaluación financiera de esos países. En general se observa que la contabilidad financiera, en términos de PIB, VAB o RN, parece no concordar con los resultados obtenidos con una contabilidad biofísica (Wackernagel et al., 2019).

Indicadores como el Producto o la Renta Nacional, medidas ampliamente usadas para evaluar los resultados de la economía nacional, debido a la forma y los propósitos para los que fueron concebidos, ignoran los costes ambientales, las tasas de agotamiento de los recursos naturales y, paradójicamente, incorpora la reparación de daños ambientales como valor añadido a la producción total. Más aún, tanto el PIB como la mayoría de los sistemas de contabilidad nacional dan cuenta de lo que ocurre dentro de las fronteras nacionales y, generalmente, no informan de la insoste- 
nibilidad generada por acciones aisladas en cada país y los impactos del crecimiento económico sobre la biosfera y sobre terceros países (Giannetti et al.,2015). De hecho, un país puede estar importando sostenibilidad, apoyado en su mayor capacidad de compra, generando disfunciones e insostenibilidad en países con una capacidad de compra más reducida.

Un concepto significativo, a este respecto, es el de deuda ecológica ${ }^{6}$, relacionado con el de justicia ambiental, que pone de relieve la división territorial existente aquellos países donde tiene lugar la función de apropiación y consumo de los recursos naturales y aquellos otros donde tiene lugar la función extractivas y, en muchas ocasiones, de depósito de los desechos generados.

Joan Martínez Alier y Jordi Roca Jusmet (2001) se acercan a esta idea relacionándola con la deuda externa:

¿Cuáles son las relaciones entre la deuda externa y la deuda ecológica? Son relaciones que abarcan dos aspectos principales. Primero, el reclamo de la deuda ecológica, a cuenta de la exportación mal pagada (pues los precios no incluyen diversos costos sociales y ambientales, locales y globales) y de los servicios ambientales proporcionados gratis [...]. El segundo aspecto de las relaciones entre ambas deudas ha sido ya más estudiado: de qué manera la obligación de pagar la deuda externa y sus intereses lleva a una depredación de la naturaleza (y por tanto aumenta la deuda ecológica). (p. 428)

Una definición operativa de deuda ecológica, que admite tanto indicadores biofísicos como monetarios, la proporciona Paredis et al. (2009):

La deuda ecológica del país A consiste en: 1) el daño ecológico causado, a lo largo del tiempo, por el país A en otros países o en otras áreas bajo la jurisdicción de otros países, a través de sus patrones de producción y consumo; y/o 2) el daño ecológico causado, a lo largo del tiempo, por el país A en ecosistemas localizados más allá de su jurisdicción nacional, a través de sus patrones de producción y consumo; y/o 3) la explotación o el uso de los ecosistemas y de los bienes y servicios ecosistémicos, a lo largo del tiempo, por parte del país A a expensas del derecho equitativo de los demás países o individuos a estos ecosistemas y a los bienes y servicios que estos proporcionan. (p. 40)

Esta aproximación permite, además, hacer algunas precisiones, entre ellas: qué se entiende por daño ecológico, cuál es la escala espacial del daño, qué son los derechos equitativos de acceso a los bienes y servicios de los ecosistemas, quiénes son los

${ }^{6}$ El concepto de deuda ecológica, en sus orígenes, puede ser interpretado como una respuesta al peso de la deuda financiera sobre muchos países en desarrollo, a partir de las publicaciones iniciales del Instituto de Ecología Política de Chile de principios de los años noventa del pasado siglo. Es por ello que, desde sus inicios, deuda externa y deuda ecológica han sido dos aspectos estrechamente relacionados. 
deudores y quiénes los acreedores y, por último, cuáles son las escalas temporales. Esta definición también puede extenderse a otros actores distintos de los países (por ejemplo, la deuda ecológica contraída por las empresas).

Vinculado a lo anterior, es importante observar la relación existente entre la seguridad de acceso a los recursos y los resultados económicos a largo plazo. En este sentido, la contabilidad biofísica, como herramienta complementaria, es útil para hacer un seguimiento de las necesidades de recursos del país, además de aportar información adicional a la habitualmente existente en términos monetarios. Ofrece, en consecuencia, una perspectiva distinta, que en muchos casos contrasta con las evaluaciones financieras de los resultados de los países. Esto puede observarse, por ejemplo, al comparar la posición en ranking mundial de los diferentes países atendiendo tanto al nivel de desarrollo económico alcanzado como al volumen de huella ecológica generada.

Como puede observarse en el Gráfico 2, existe una correlación directa entre el IDH y la HE (coeficiente de correlación de Pearson igual a 0,72). Esto que puede parecer una obviedad (esto es, a menor capacidad de consumo menor huella ecológica

\section{GRÁFICO 2}

\section{ÍNDICE DE DESARROLLO HUMANO Y HUELLA ECOLÓGICA PER CÁPITA} (2017)

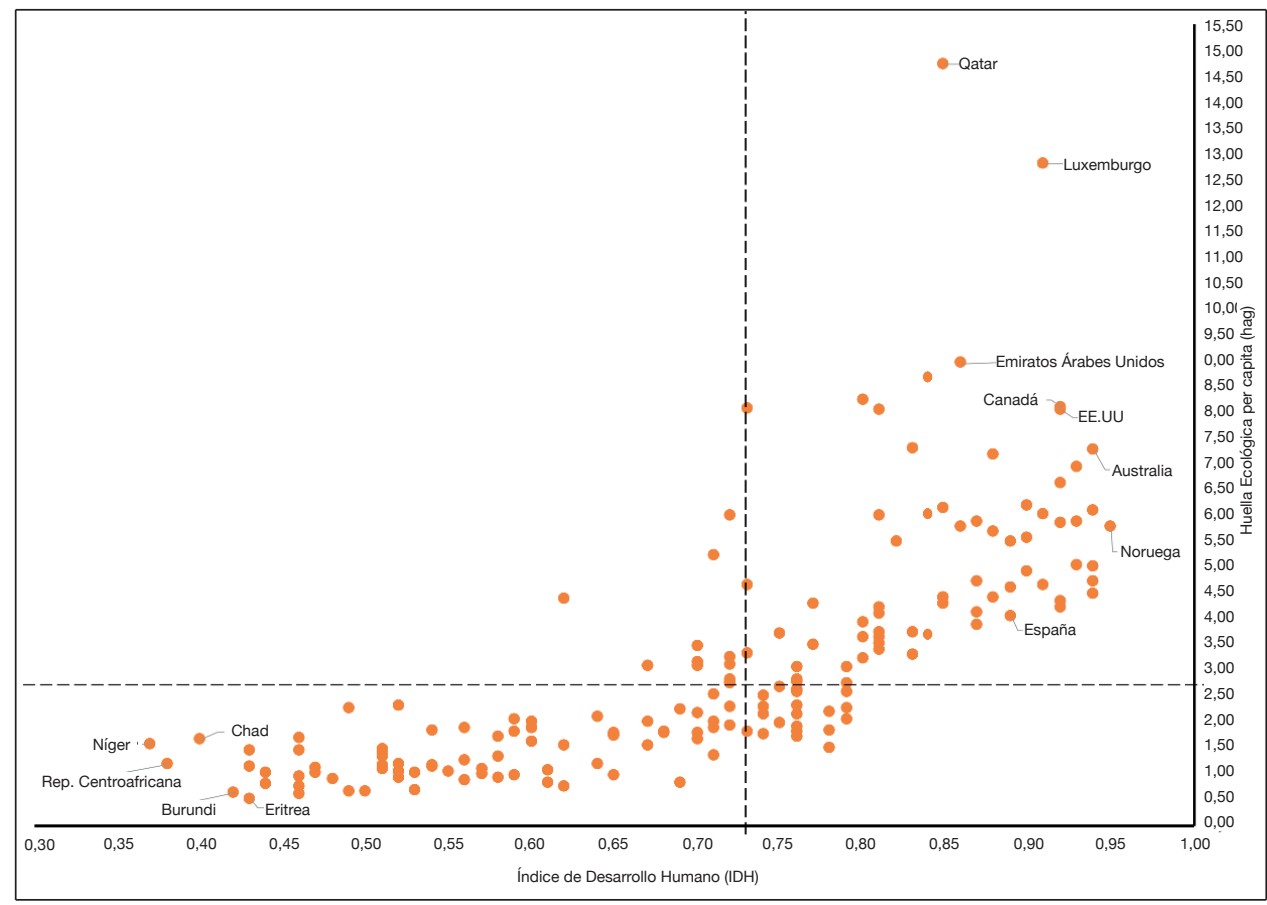

FUENTE: Elaboración propia, a partir de Global Footprint Network. 
generada) no da cuenta del hecho de que los países que originan una huella ecológica baja o en declive, presentan, también, una pérdida de áreas biológicamente productivas (biocapacidad). De hecho, en general, los países con una huella ecológica baja y escasos ingresos ven reducir su superficie biológicamente productiva (Wackernagel et al., 2019). Esto es, son países, que, de no mediar un cambio sustancial en la tendencia observada, quedarán atrapados en la «trampa de la pobreza» económica y ambiental. Esto es, su empobrecimiento lo es en un doble sentido, tanto financiero como ecológico. Para estos países, especialmente, la disponibilidad de recursos se convierte el principal factor limitante para su desarrollo. De otro lado, dado que el acceso a los recursos y la seguridad de los mismos son esenciales para el funcionamiento de las economías, se puede plantear la hipótesis de que el acceso a la biocapacidad y la actividad económica estarían positivamente correlacionadas.

Lo antes descrito es crucial desde el punto de vista de la sostenibilidad y muestra las limitaciones que las variables macroeconómicas al uso presentan para medir la actividad económica, así como la pertinencia del uso complementario de indicadores biofísicos, entre los que la huella ecológica puede jugar un papel significativo.

España presenta (Gráfico 3) un déficit ${ }^{7}$ de biocapacidad (porcentaje de la huella ecológica que excede a la biocapacidad) del 234,7\% (Global Footprint Network, 2021). En términos de superficie requerida y existente, la razón es de 3,69; esto es, para satisfacer los requerimientos metabólicos de consumo y absorción de desechos de la población española se necesitan aproximadamente 3,7 países con extensión similar a la superficie del territorio español.

Como puede observarse en el Gráfico 4, a la superficie destinada a la absorción de $\mathrm{CO}_{2}$ (huella de carbono ${ }^{8}$ ) le sigue la superficie agrícola, con un $20,42 \%$ de participación en la huella ecológica total. Es este un componente importante de la huella ecológica total no solo por la extensión de terreno ocupado sino, también, y esto suele quedar oculto, por los inputs utilizados (energía, agua y nutrientes) que añaden a los requerimientos territoriales asociados al uso del suelo para la práctica agrícola y que incorporan hectáreas adicionales; en términos de hectáreas globales, la superficie agrícola española presenta un déficit del $21,3 \%$. A escala planetaria la superficie total de las tierras agrícolas representa el $38 \%$ de la superficie terrestre del planeta (y casi el 50\% de su superficie vegetal), es responsable del 69\% de las extracciones

\footnotetext{
7 Un déficit ecológico se produce cuando la huella ecológica de una población excede la biocapacidad del área disponible para esa población. Un déficit ecológico nacional, regional o local significa que la nación, la región o la localidad está importando biocapacidad a través del comercio, liquidando bienes ecológicos nacionales, regionales o locales o emitiendo residuos de dióxido de carbono a la atmósfera. En cambio, hablaremos de reserva ecológica cuando la biocapacidad de una nación, región o localidad excede la huella ecológica de su población.

${ }^{8}$ La huella de carbono representa la superficie de terreno forestal necesaria para secuestrar las emisiones antropogénicas de dióxido de carbono. En el manual National Footprint and Biocapacity Accounts (NFA) 2019 se calcula la huella de las emisiones de dióxido de carbono utilizando varios parámetros, entre los que se incluyen la combustión de combustibles fósiles domésticos y el uso de electricidad, el carbono incorporado en los artículos comercializados y la electricidad, la cuota de un país en las emisiones mundiales del transporte internacional y las fuentes no fósiles. El factor de equivalencia para esta superficie es de 1,28 (Global Footprint Network, 2021).
} 


\section{GRÁFICO 3 \\ EVOLUCIÓN DE HUELLA ECOLÓGICA Y BIOCAPACIDAD, ESPAÑA}

$($ Base $100=1961)$

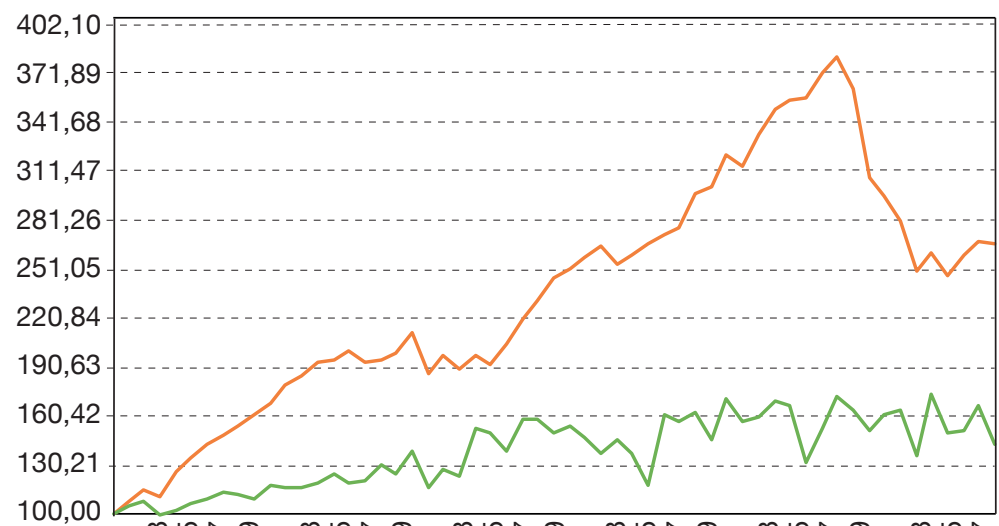

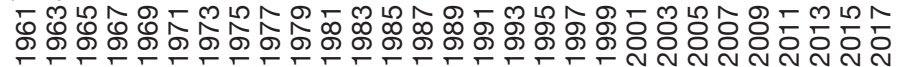

— Huella ecológica — Biocapacidad

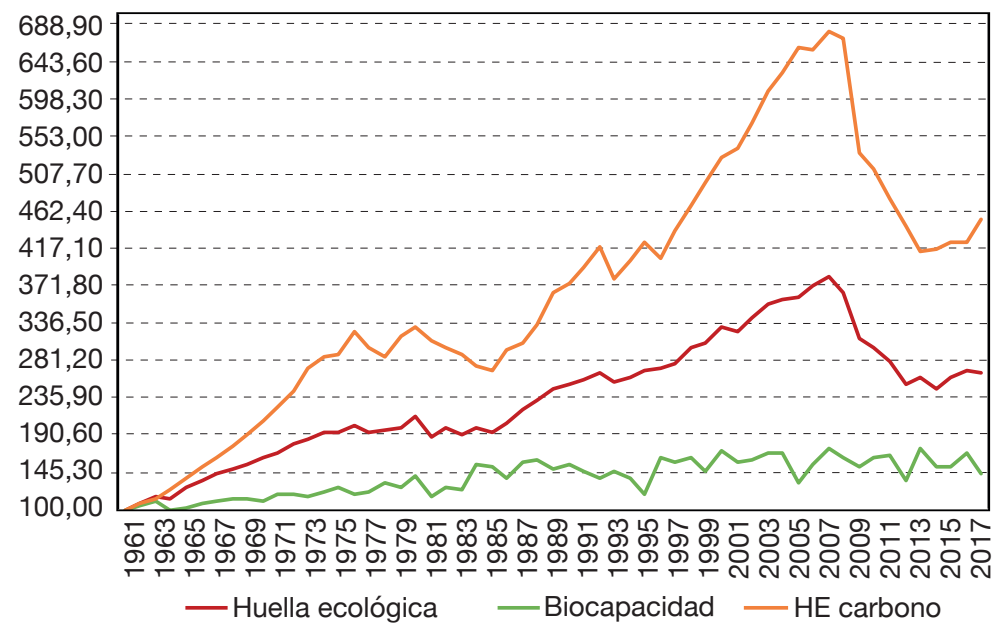

FUENTE: Elaboración propia, a partir de Global Footprint Network.

de agua dulce y, junto con el resto del sistema alimentario, y es responsable de entre el 25 y el $30 \%$ de las emisiones mundiales de gases de efecto invernadero (Gladek et al., 2017). Es, por tanto, el sector agroalimentario un sector clave en la estimación de la huella ecológica, tanto local como global. En el caso español, en 2018 se movieron 238,99 miles de millones de toneladas por kilómetro de productos agrícolas. El total de toneladas exportadas ascendió 34,98 millones, el 76,57\% de las cuales tuvieron como destino los países de la Unión Europea (UE-28). Las importaciones ascendieron a 43,93 millones de toneladas, el 43,38\% correspondieron a países de la UE-28, de las toneladas procedentes del resto del mundo, algo más del $56 \%$, cinco 


\section{GRÁFICO 4 \\ EVOLUCIÓN DE LA HUELLA ECOLÓGICA PER CÁPITA, ESPAÑA (Componentes, hag)}
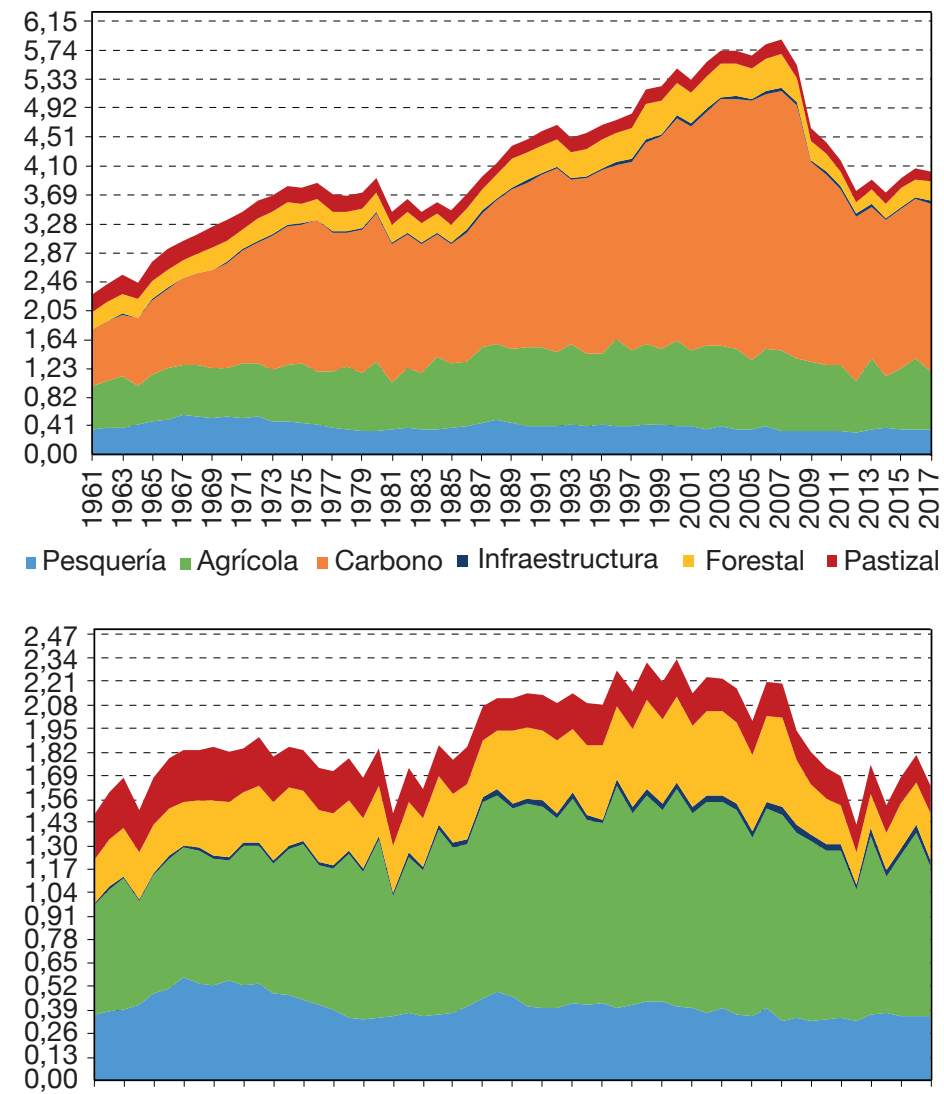

б

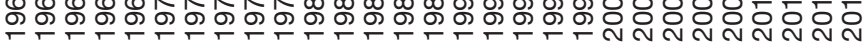

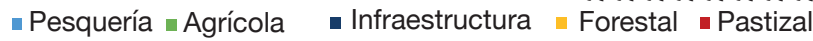

FUENTE: Elaboración propia, a partir de Global Footprint Network.

países: Brasil (12,5\%), Ucrania (11,1\%), USA (8,7\%), Argentina (4,6\%) e Indonesia $(2,9 \%)$, concentran el 39,8\% de las importaciones totales. Los más de 43 millones de toneladas de alimentos, importados en 2018, recorrieron cerca de $7.000 \mathrm{~km}$ y generaron más de 6.500 millones de toneladas de $\mathrm{CO}_{2}$ (MINCOTUR, 2019). Desde un punto de vista comparativo, las importaciones de productos alimentarios españoles representan un 1,5\% del total de las importaciones mundiales de estos productos, y un $2,3 \%$ de las exportaciones mundiales, muy por encima de su representación en cuanto a población o superficie. Esto ilustra la dimensión de la producción agroalimentaria y su impacto ambiental. 
Una sección básica de la estimación de la huella ecológica es el consumo energético, debido al consumo de combustibles fósiles, su principal componente, para la producción de energía, que concentra, en 2017, el 59,37\% de la huella ecológica total (Gráfico 5). Veamos su comportamiento con algo más de detalle para la realidad española.

En 2018, en España, los combustibles de origen fósil concentraban el $74 \%$ del total de energía primaria consumida (Cuadro 5). La evolución del consumo de energía primaria en las tres últimas décadas se recoge en el Gráfico 6.

En el Gráfico 7 puede observarse existe una fuerte correlación entre el consumo de energía y la huella de carbono (coeficiente de correlación de Pearson, 0,95). Tanto el consumo de energía como la huella de carbono crecen y decrecen más que propor-

\author{
GRÁFICO 5 \\ HUELLA ECOLÓGICA, ESPAÑA \\ (En \%)
}

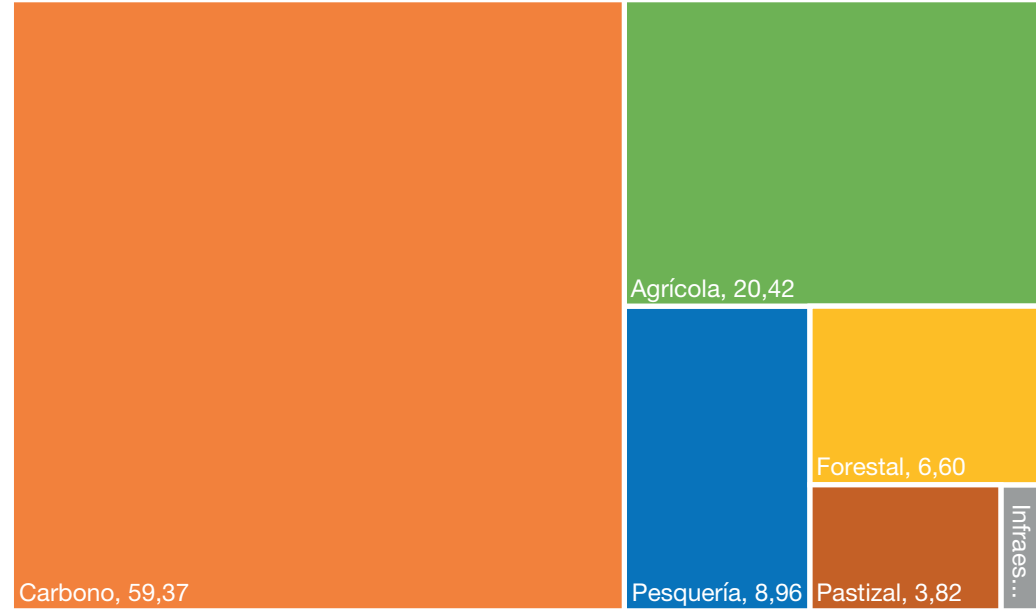

FUENTE: Elaboración propia, a partir de Global Footprint Network.

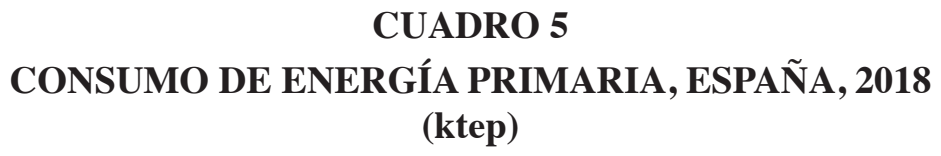

\begin{tabular}{|c|c|c|c|c|c|c|c|c|}
\hline & Total & Carbón & $\begin{array}{c}\text { Productos } \\
\text { petro- } \\
\text { líferos }\end{array}$ & $\begin{array}{c}\text { Gas } \\
\text { natural }\end{array}$ & $\begin{array}{c}\text { Reno- } \\
\text { vables }\end{array}$ & $\begin{array}{c}\text { Residuos } \\
\text { no re- } \\
\text { novables }\end{array}$ & Nuclear & $\begin{array}{c}\text { Saldo } \\
\text { eléctrico }\end{array}$ \\
\hline ktep & 129.813 & 11.516 & 57.512 & 27.082 & 17.944 & 325 & 14.479 & 955 \\
\hline$\%$ & 100,00 & 8,87 & 44,30 & 20,86 & 13,82 & 0,25 & 11,15 & 0,74 \\
\hline
\end{tabular}

FUENTE: Elaboración propia, a partir de Ministerio para la Transición Ecológica y el Reto Demográfico (MITECO, 2018). 


\section{GRÁFICO 6 \\ CONSUMO DE ENERGÍA PRIMARIA, ESPAÑA (1990-2018) \\ (Fuentes, ktep)}

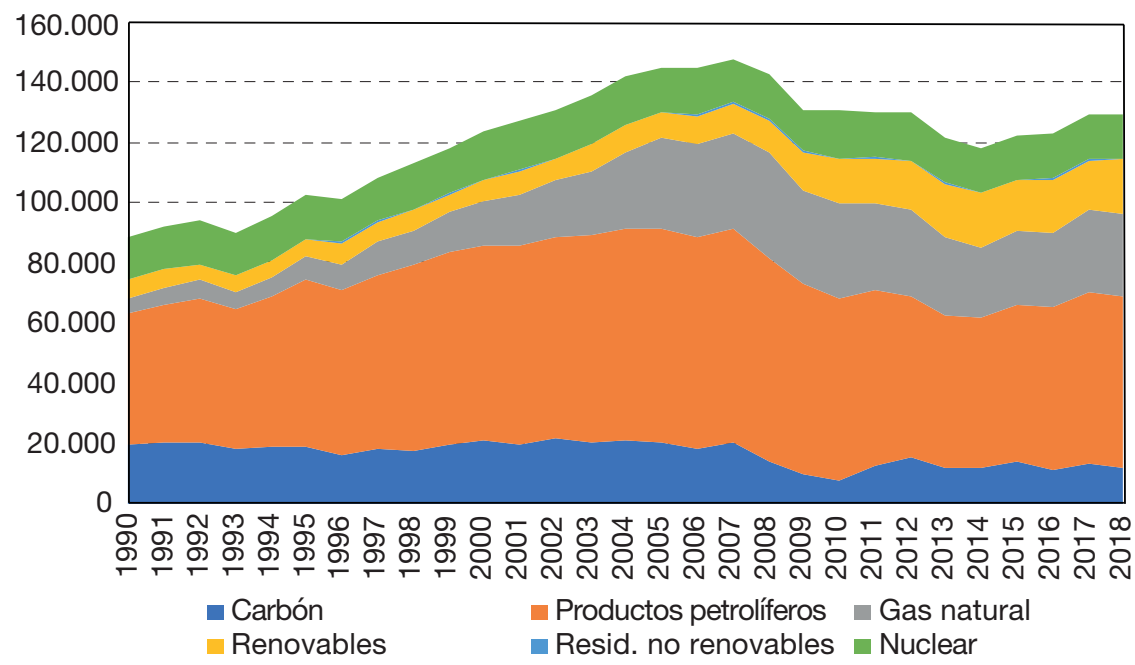

FUENTE: Elaboración propia, a partir de Ministerio para la Transición Ecológica y el Reto Demográfico (MITECO).

\section{GRÁFICO 7 \\ EVOLUCIÓN DEL PIB, CONSUMO DE ENERGÍA PRIMARIA Y HUELLA DE CARBONO, ESPAÑA (Base 100=1965)}

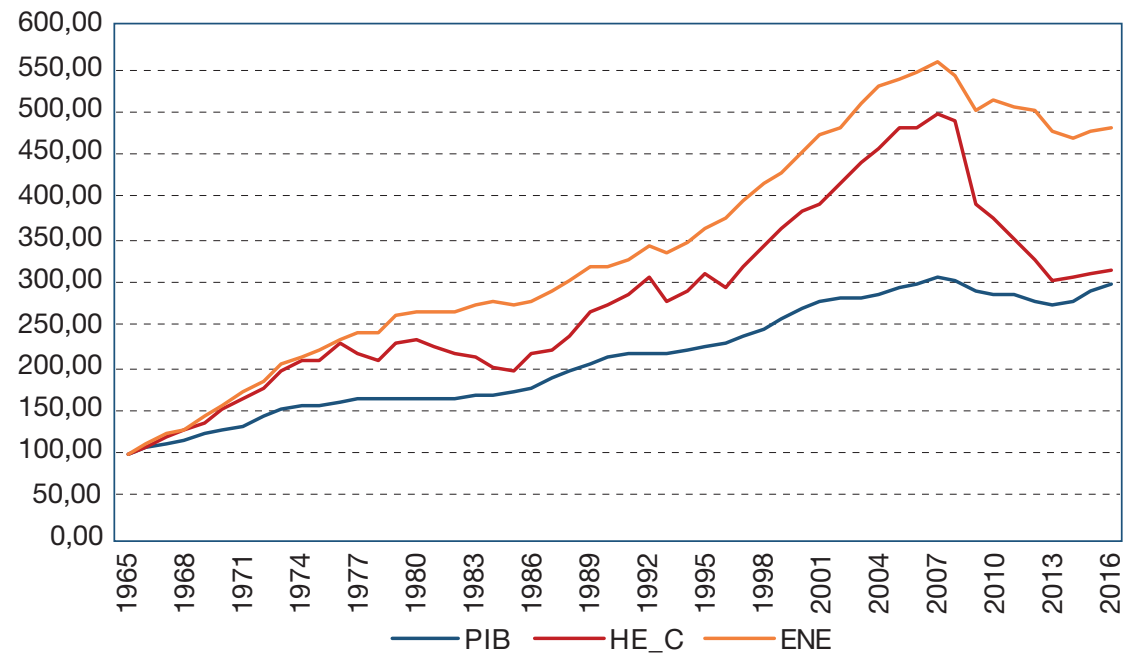

FUENTE: Elaboración propia, a partir de Banco Mundial, Global Footprint Network y MITECO. 
cionalmente a lo que hace el PIB y la huella ecológica total. Esto no solo describe el hecho de que la huella de carbono es el principal componente de la huella ecológica, que representa aproximadamente el $60 \%$ de la huella ecológica total (Gráfico 8), sino que el crecimiento económico, expresado en términos de PIB, y huella ecológica no se comportan exactamente igual.

\section{GRÁFICO 8}

\section{EVOLUCIÓN DE LA HUELLA DE CARBONO, ESPAÑA (1961-2017) \\ (En \% sobre la Huella Ecológica total)}

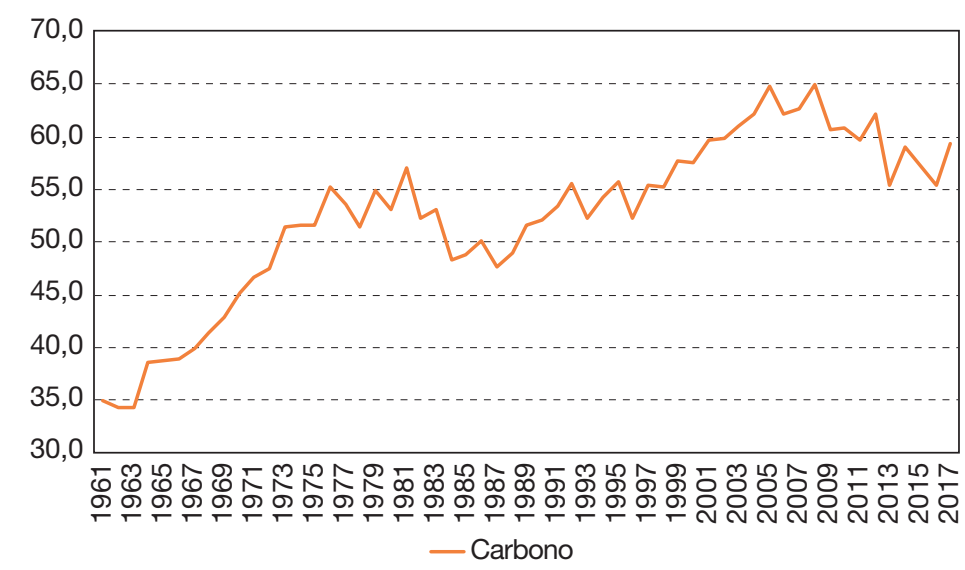

FUENTE: Elaboración propia, a partir de Global Footprint Network.

Algunos trabajos de investigación han tratado la relación entre el crecimiento económico, en términos de PIB, y la huella ecológica (ver, entre otros, Stern, 2004; Hervieux \& Darné, 2013; Al-Mulali et al., 2015; Ulucak \& Bilgili, 2018; Ansari et al., 2020), a través del análisis de la denominada Curva de Kuznets Ambiental (CKA), por similitud con la relación que Simon Kuznets, a mediados de los años cincuenta del pasado siglo, estableciera entre el crecimiento económico y el aumento de la desigualdad en la distribución de la renta.

Para la economía española pueden verse, a este respecto, los trabajos de Óscar Carpintero (2005), que originariamente trató en su tesis doctoral, en la que estudia la evolución de la huella ecológica para España, y discute la hipótesis de la Curva de Kuznets Ambiental, para el periodo comprendido entre 1955 y 2000. También puede mirarse el trabajo de Esteve y Tamarit (2012), donde se relacionan las emisiones de $\mathrm{CO}_{2}$ y la renta per capita de la economía española desde 1857 a 2007. Son series temporales, las utilizadas en estos trabajos, muy largas y esto permite una mayor compresión de estas relaciones.

En concreto, con datos correspondientes al periodo comprendido entre 1960 y 2017, la hipótesis de la CKA no parece confirmarse. Esto es, la forma de U invertida no se observa (Gráfico 9), al menos, durante este periodo, cuando relacionamos el PIB (valores constantes año 2015) con las emisiones de $\mathrm{CO}_{2}$ (ktep). Es más, como se ha 


\section{GRÁFICO 9 \\ EMISIONES DE CO, Y PIB, ESPAÑA (1960-2017) \\ (ktep y euros constantes de $2015, \log _{10}$ )}

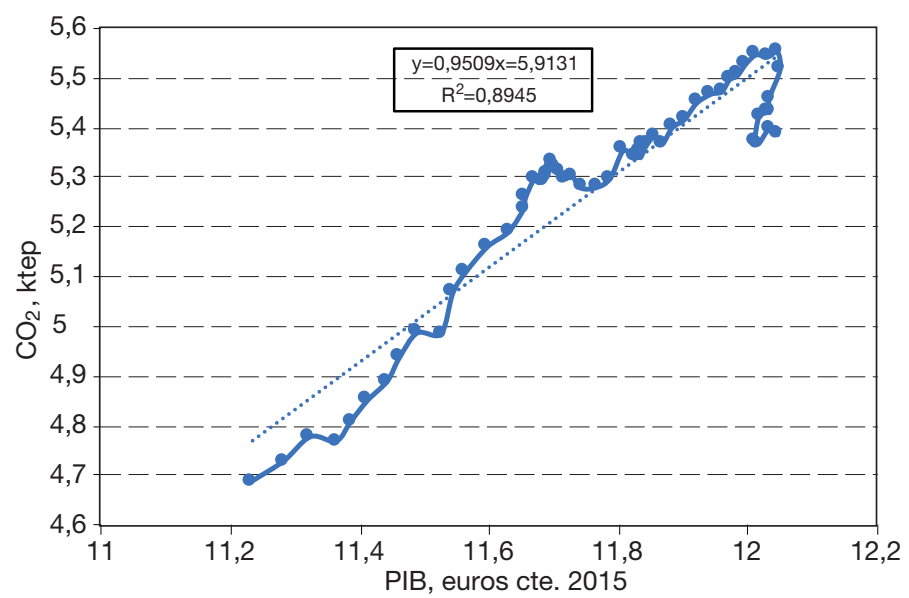

FUENTE: Elaboración propia, a partir de Banco Mundial.

indicado antes la huella de carbono crece más que proporcionalmente al crecimiento del PIB. Por tanto, la huella ecológica, que traduce a toneladas equivalentes de $\mathrm{CO}_{2}$ los requerimientos humanos de recursos y la generación de desechos, en el caso y para el periodo de tiempo analizado, discute la hipótesis de que a medida que aumenta la renta las emisiones de contaminantes, o la huella ecológica generada, disminuye 9 .

En estudios realizados sobre la aplicación de la huella ecológica, para testar la hipótesis de la curva de Kuznets ambiental, se utilizaron distintas aproximaciones econométricas (York et al., 2004; Caviglia-Harris et al., 2009; Hervieux \& Darné, 2013; Uddin et al., 2017; Ulucak \& Bilgili, 2018; Wang \& Dong, 2019; Altıntaş \& Kassouri, 2020; Lee \& Chen, 2021), que no encontraron evidencia empírica que permitiesen sostener las asunciones sobre la curva de Kuznets ambiental. En cualquier caso, en este trabajo por razones de espacio y en aras de la simplicidad hemos recurrido a la aproximación lineal, observándose que la relación lineal estadística entre el PIB y las emisiones de $\mathrm{CO}_{2}$ o la huella de carbono muestra que el comportamiento es similar; esto es, incrementos del PIB se alinean positivamente con crecimientos tanto de las emisiones de $\mathrm{CO}_{2}$ como de la huella de carbono generada por la economía española, para el periodo de tiempo analizado (Gráficos 9 y 10).

${ }^{9}$ El propio Simon Kuznets (1955), reconoce, en Economic Growth and Income Inequality, que: «Al concluir este documento, soy muy consciente de la escasez de información fiable presentada» (p. 26). El documento contiene tal vez un $5 \%$ de información empírica y un $95 \%$ de especulaciones, algunas de las cuales posiblemente estén contaminadas por deseos. La duda expresada por Kuznets parece sensata para su época, también podría serlo para la actual, donde la excesiva financiarización de la actividad económica y su importante volatilidad requiere ciertas dosis de especulación, aunque también de prudencia ante fenómenos tan complejos y cambiantes. 


\section{GRÁFICO 10}

HUELLA DE CARBONO Y PIB, ESPAÑA (1961-2017)

(hag y euros constantes de 2015, $\log _{10}$ )

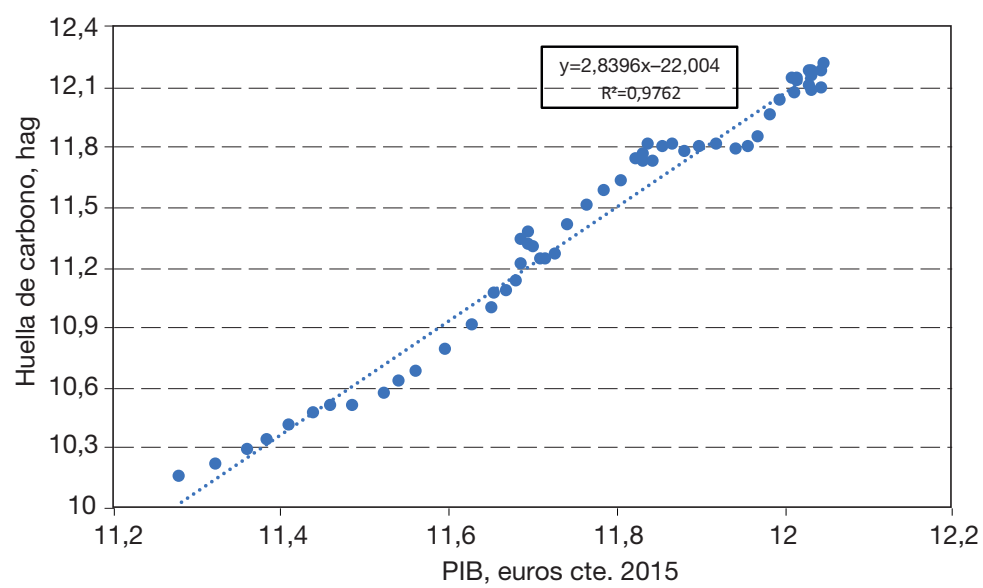

FUENTE: Elaboración propia, a partir de Banco Mundial y Global Footprint Network.

Otro de los tipos de superficie que participan en el agregado total de la huella ecológica, aunque represente cuantitativamente un porcentaje relativamente reducido de esta, son las áreas ocupadas por infraestructuras o urbanizadas. Dentro de esta categoría, especialmente importante en el análisis de la huella ecológica, tanto cuantitativamente como cualitativamente, se encuentra el espacio urbanizado (las ciudades). De hecho, las ciudades juegan un papel clave en el contexto de la sostenibilidad. Es necesario entender que la ciudad constituye un nodo espacial de intenso consumo de energía y materiales y de generación de residuos. Más aún, los recursos demandados y los residuos generados, para satisfacer las exigencias metabólicas de la ciudad, dependen de un área adicional de ecosistemas tanto productivos como de asimilación de desechos que suele ser de 200 a 1.000 veces mayor que su demarcación política o geográfica (Rees, 2018), superando, a veces, el límite superior de este rango. Esta superficie extraurbana o adicional se corresponde con los requerimientos de biocapacidad de la ciudad y representa su huella ecológica. Las ciudades pueden mostrar una gran capacidad de resiliencia, pero, al mismo tiempo, revelan una enorme fragilidad y vulnerabilidad al depender, para satisfacer sus exigencias metabólicas, de hábitats ajenos, en general muy alejados, al territorio que ocupan. Sin estos últimos, en las condiciones actuales, cualquier ciudad perecería.

En este sentido, uno de los problemas más importantes en la territorialización de la huella ecológica es la falta de datos existentes a nivel municipal o escala local, para poder estimar con precisión el comportamiento de las ciudades, sus necesidades metabólicas, en definitiva, su huella ecológica. Para suplir esta carencia, generalmente, se ha usado la población como factor de asignación de la huella ecológica a 
cada localidad, a partir del valor correspondiente al país o nación al que pertenece, que no deja de ser, como los datos agregados, un promedio del conjunto del territorio. Este criterio asume, implícitamente, que el comportamiento de las poblaciones es homogéneo, lo cual contradice la idea originaria con la que fue pensado el indicador; esto es, el factor determinante de la huella ecológica generada por los seres humanos son sus pautas de consumo, y esta tiene lugar en las ciudades, nadie vive en un territorio abstracto, el hábitat de cada ser humano es el urbano, aunque este no tenga los límites definidos, como se ha comentado antes, al disponer, para cubrir los requerimientos de consumo y verter los desechos generados, del conjunto del planeta. El consumo, pues, podría utilizarse como factor de ponderación para asignar a cada municipio la huella ecológica específica. De este modo, mitigaríamos, aunque parcialmente, la carencia de datos a nivel municipal para poder realizar una estimación de la huella a esta escala territorial.

Cuando parcialmente podemos disponer de variables de consumo suficientemente relevantes, con una fuerte correlación con el consumo total, puede recurrirse al método de los componentes principales, como procedimiento de estimación indirecta, para, de este modo, determinar los factores de ponderación en la asignación de la huella a cada localidad. Por ejemplo, el consumo de electricidad, los residuos sólidos urbanos, el parque de vehículo, el parque de viviendas, las plazas de hostelería y restauración, el número de establecimientos empresariales o comerciales (Cano-Orellana, 2004; Cano-Orellana \& Delgado-Cabeza, 2015), suelen ser variables, y algunas otras, expresadas en unidades físicas, sobre las que existe información a nivel local, aunque el hecho de que no haya un criterio armonizador a nivel estatal dificulta su uso para todo el territorio ciudad a ciudad. Una vía podría ser hacer esto a nivel de comunidad autónoma, que, además, si esto es posible, tomaría como referencia la estimación de la huella ecológica de la comunidad autonómica correspondiente en lugar de la estatal.

En el caso de los municipios españoles, dada la carencia de datos a nivel municipal, se ha recurrido, para la asignación de la huella, a la renta media de los municipios como variable proxy. Esto ha permitido establecer una relación entre la dinámica de localización de la población española y la huella ecológica generada.

Con la información disponible a partir de la Agencia Tributaria española, el Instituto Nacional de Estadística, el Instituto de Estadística de Navarra, el Instituto Vasco de Estadística y Foro Ciudad, se ha podido estimar la renta media de los 8.131 municipios españoles (Mapa 3). Este dato, como se indicó antes, es el utilizado para asignar la huella municipal, como factor de ponderación. A nuestro criterio, ponderar por algunas de las variables más relevantes de consumo, como puede ser la renta, permite una mejor aproximación a la huella ecológica generada que la población. De hecho, lo que se hace implícitamente es discriminar a la población en función de capacidad de consumo. Evidentemente, esto no deja de ser una aproximación, y lo deseable es disponer de un banco de datos suficiente a escala local, municipio a municipio, de manera que sea factible una aproximación más precisa. En aquellas comunidades autónomas en que la información estadística lo permita, lo deseable es 


\section{MAPA 3}

\section{DISTRIBUCIÓN DE LA HUELLA ECOLÓGICA EN LOS MUNICIPIOS} ESPAÑOLES (2017)

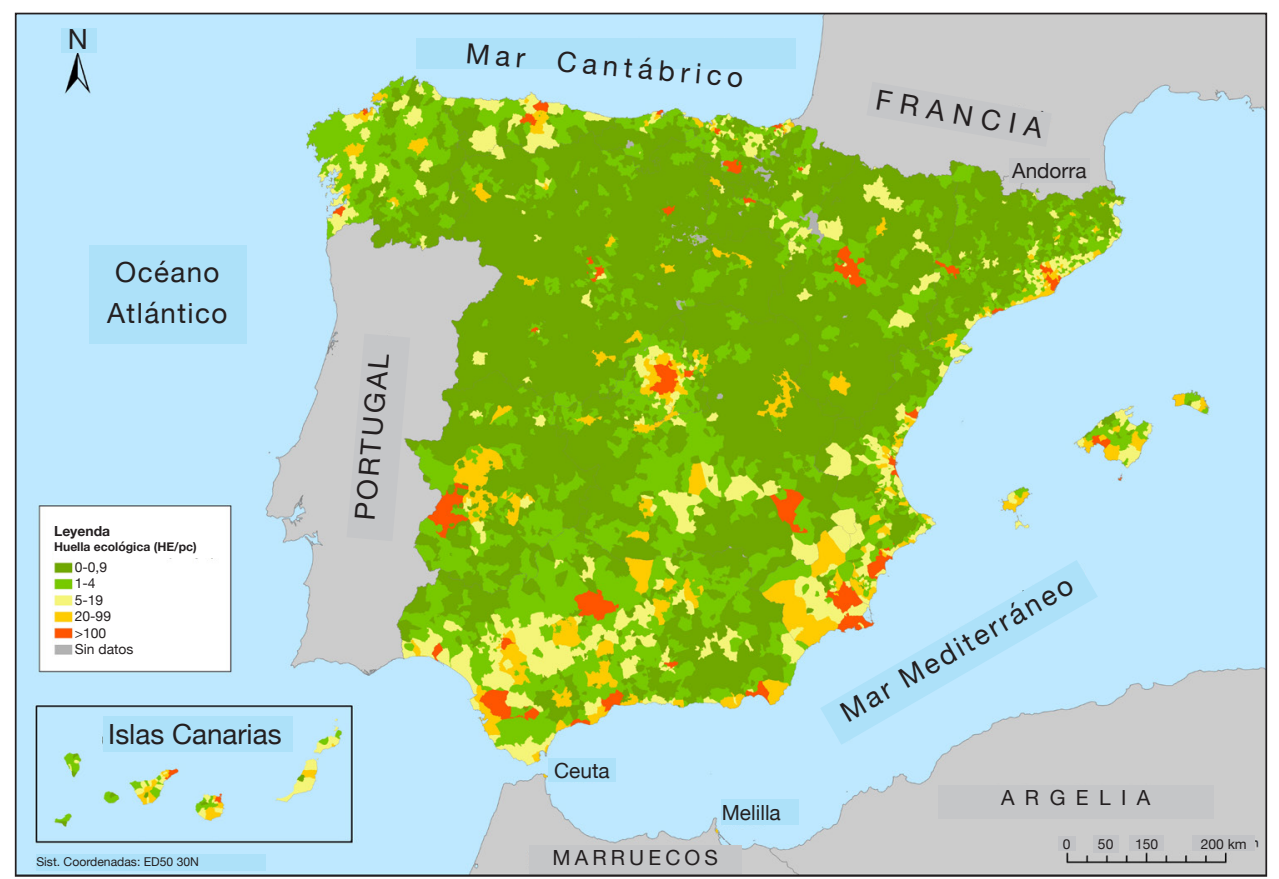

FUENTE: Elaboración propia a partir de las fuentes citadas en el texto.

contar con un set de variables que, a través, como ya se ha indicado, del método de los compontes principales se pueda determinar un factor que permita la asignación de la huella ecológica regional, más cercana que la del territorio estatal.

Como puede apreciarse en el mapa la huella ecológica se concentra en las grandes conurbaciones y el litoral. Cabe indicar que tan solo 187 municipios (que representan el 2,3\% de los 8.131 municipios, el 56,4\% de la población, el 64,6\% de la renta total y ocupan el 6,4\% del territorio) concentran el $99 \%$ de la huella total generada. Esto es, aquellos lugares con mayor densidad de población (187 municipios: 817,5 hab. $/ \mathrm{km}^{2}$; España: 93,2 hab. $/ \mathrm{km}^{2}$ ) y mayor concentración de rentas, concentran una huella ecológica más que proporcional al volumen de población y de renta. El propósito de este trabajo, no obstante, es el de abrir una vía para la aproximación y el cálculo de la huella ecológica hacia realidades que cada vez adquieren mayor protagonismo en la planificación y gestión de la sostenibilidad, pero que se han estudiado escasamente debido a la falta de datos. Estas realidades son los municipios, especialmente las grandes ciudades y conurbaciones, así como aquellos situados en localizaciones especialmente frágiles, como son los municipios costeros, sometidos a una extraordinaria y sostenida presión. 
Para concluir este apartado hay dos aspectos sobre los que convendría tener en consideración. De una parte, las iniciativas tendentes a mitigar la huella ecológica generada creando sumideros de carbono, o compensándola con la generación y desarrollo de espacios verdes, especialmente en las grandes ciudades. De otra, afrontar las limitaciones que presenta la huella ecológica como indicador.

En relación con las primeras, es interesante mirar los trabajos publicados con este tema en Encyclopedia of Energy, especialmente el artículo de Lal (2004), así como explorar las distintas iniciativas que para este fin se están proponiendo y desarrollando.

En cuanto a las limitaciones del indicador se han planteado varias, a pesar de la popularidad y aceptación que ha ido ganando con el tiempo. Una que es especialmente relevante, a nuestro juicio, es la incapacidad de la huella ecológica para seguir el agotamiento de las reservas de capital natural inducido por el hombre. Para ello, Mancini et al. (2017) proponen abrir una vía de investigación que se ocupe de establecer la distinción entre el uso de las reservas y el uso de los flujos de capital natural e incorporar esto en la contabilidad de la huella ecológica.

\section{Conclusiones}

Prácticamente desde su aparición a principios de los años noventa del pasado siglo la huella ecológica ha ido ganando protagonismo como indicador utilizado para la evaluación, planificación y gestión de la sostenibilidad. En su concepción y diseño el territorio siempre jugó un papel importante, así como el deseo de ofrecer, a través de un índice fácil de interpretar, las limitaciones biofísicas existentes para satisfacer los requerimientos irrefrenables de recursos naturales por los seres humanos. Tal es su vocación territorial que el índice que promueve se expresa en hectáreas. Es, por tanto, una útil herramienta de comunicación y un indicador adecuado para evaluar la sostenibilidad territorial. En este trabajo, tomando como referencia la realidad del Estado español, se ha analizado la relación entre las pautas de localización seguida por la población española y su impacto ambiental en el territorio. Como contexto para el análisis se estudió la evolución de la localización espacial de la población española desde el inicio del pasado siglo hasta la actualidad. Esto permitió concluir que el territorio español desde hace más de 100 años ha vivido un constante vaciamiento de parte de su territorio. Situación que lejos de mitigarse se acentuó entre los años sesenta y ochenta, y se ha mantenido hasta ahora. Así, en 2019, el 50,06\% de la población ocupaba tan solo el 4,8\% del territorio, concentrada principalmente en las grandes conurbaciones y el litoral. Esta particular localización está asociada a una creciente huella ecológica. De hecho, con los datos disponibles correspondientes a 2017, en términos de huella ecológica, para cubrir los requerimientos de recursos y absorber los desechos generados por la población española se necesitan del orden de 3,7 territorios como el español.

Un aspecto importante que singulariza este trabajo es haber estimado la huella ecológica de los 8.131 municipios españoles. De acuerdo con los resultados obte- 
nidos se puede concluir que la densidad de población y su capacidad de consumo, medida a través de la renta media de los municipios, genera una huella ecológica más que proporcional al volumen tanto de población como de renta. Tan solo 187 municipios concentran el $99 \%$ de la huella total. Este intento de bajar la escala territorial de análisis de la huella ecológica se vería reforzado si se dispusiera de un banco de datos, no solo monetarios, a escala municipal, capaz de informar de los patrones de consumo en los que incurren las diferentes poblaciones y territorios. Este asunto es clave desde el punto de vista de la sostenibilidad. Los grandes agregados tienen utilidad en algunos aspectos, pero la evaluación de la sostenibilidad demanda un tipo de indicadores más cercanos y desagregados. La huella ecológica de las ciudades inspiró a Rees y Wackernagel a proponer el indicador de huella ecológica, la carencia de datos en esta escala territorial ha frustrado, al menos hasta ahora, ese propósito. Si la población se localiza mayoritariamente en las ciudades y es en ellas donde está la clave para avanzar hacia una sociedad sostenible, la nula o escasa información existente para esta escala territorial dificulta extraordinariamente la evaluación, planificación y gestión de la sostenibilidad. Esperemos que esta información mejore y podamos avanzar en el cumplimiento de este propósito.

\section{Referencias bibliográficas}

Alier, J. M., \& Jusmet, J. R. (2001). Economía Ecológica y Política Ambiental. Fondo de Cultura Económica.

Al-Mulali, U., Weng-Wai, C., Sheau-Ting, L., \& Mohammed, A. H. (2015). Investigating the environmental Kuznets curve (EKC) hypothesis by utilizing the ecological footprint as an indicator of environmental degradation. Ecological Indicators, 48, 315-323.

Ansari, M. A., Ahmad, M. R., Siddique, S., \& Mansoor, K. (2020). An environment Kuznets curve for ecological footprint: Evidence from GCC countries. Carbon Management, 11(4), 355-368.

Altıntaş, H., \& Kassouri, Y. (2020). Is the environmental Kuznets Curve in Europe related to the per-capita ecological footprint or CO2 emissions? Ecological Indicators, 113, 106187.

Banco Mundial. https://datos.bancomundial.org/

BloombergNEF (2020). Oil Demand From Road Transport: Covid-19 and Beyond. https://www.about.bnef.com/blog/oil-demand-from-road-transport-covid-19-and-beyond/

BP (2020). Statistical Review of World Energy. http://www.bp.com/statisticalreview

Cano-Orellana,A.(2004). Economía y sostenibilidad en las grandes aglomeraciones urbanas: aproximación al cálculo de la huella ecológica de Sevilla y su área metropolitana. Sevilla Global.

Cano-Orellana, A., \& Delgado-Cabeza, M. (2015). Local ecological footprint using Principal Component Analysis: A case study of localities in Andalusia (Spain). Ecological Indicators, 57, 573-579.

Carpintero, Ó. (2005). El metabolismo de la economía española. Recursos naturales y huella ecológica (1955-2000). Fundación César Manrique. http://www.fcmanrique.org/recursos/publicacion/elmetabolismo.pdf

Catton, W. R. (1980). Overshoot: The Ecological Basis of Revolutionary Change. University of Illinois Press. 
Catton, W. R. (1986). Carrying Capacity and the Limits to Freedom. Social Ecology Session, 1. XI World Congress of Sociology.

Catton Jr, W. R. (2009). Bottleneck: Humanity's Impending Impasse: Humanity's Impending Impasse. Xlibris Corporation.

Caviglia-Harris, J. L., Chambers, D., \& Kahn, J. R. (2009). Taking the "U” out of Kuznets: A comprehensive analysis of the EKC and environmental degradation. Ecological Economics, 68(4), 1149-1159.

Chatham House (2018). Resource Trade Earth. http://resourcetrade.earth/

Common, M., \& Stagl, S. (2008). Introducción a la Economía Ecológica. Revertè.

Constanza, R. (1997). La economía ecológica de la sostenibilidad: invertir en capital natural. En R. Goodland, H. E. Daly, S. El Serafy \& B. von Droste (eds.), Medio ambiente y desarrollo sostenible: más allá del Informe Brundtland (pp. 103-114). Trotta.

Daly, H. E. (1999). Ecological economics and the ecology of economics: essays in criticism. Edward Elgar Published.

Daly, H. E., Vettese, T., Pollin, R., Burton, M., \& Somerville, P. (2019). Decrecimiento vs Green New Deal. New Left Review, en español. Traficantes de Sueños. https://raficantes.net/sites/default/files/pdfs/documentos_nlr_5_web.pdf

Esteve, V., \& Tamarit, C. (2012). Threshold cointegration and nonlinear adjustment between $\mathrm{CO} 2$ and income: the environmental Kuznets curve in Spain, 1857-2007. Energy Economics, 34(6), 2148-2156.

European Commission (2019). A European Green Deal. https://ec.europa.eu/info/strategy/priorities-2019-2024/european-green-deal_en

Ewing, B., Reed,A., Galli,A., Kitzes, J., \& Wackernagel, M.(2010).Calculation methodology for the national footprint accounts. Global Footprint Network.

Galli, A., Iha, K., Pires, S. M., Mancini, M. S., Alves, A., Zokai, G., Lin, D., Murthy, A., \& Wackernagel, M. (2020). Assessing the ecological footprint and biocapacity of Portuguese cities: Critical results for environmental awareness and local management. Cities, 96, 102442. https://www.sciencedirect.com/science/article/pii/S0264275119302306

Galvin, R., \& Healy, N. (2020). The Green New Deal in the United States: What it is and how to pay for it. Energy Research \& Social Science, 67, 101529. https://doi.org/10.1016/j.erss.2020.101529

Georgescu-Roegen, N. (1975). Energy and economic myths. Southern Economic Journal, 41(3), 347-381.

Georgescu-Roegen, N. (1996). La Ley de Entropía y el Proceso Económico. Fundación Argentaria-Visor Distribuciones.

Giannetti, B. F., Agostinho, F., Almeida, C. M. V. B., \& Huisingh, D. (2015). A review of limitations of GDP and alternative indices to monitor human wellbeing and to manage eco-system functionality. Journal of cleaner production, 87, 11-25. http://www.advancesincleanerproduction.net/papers/journals/2014/2014_jcp.pdf

Gladek, E., Fraser, M., Roemers, G., Muñoz, O., Kennedy, E., Hirsch, P. (2017). The Global Food System: An Analysis. Metabolic, commissioned by WWF Netherlands. https://www.metabolic.nl/publications/global-food-system-an-analysis-pdf/

Global Footprint Network. https://www.footprintnetwork.org/our-work/earth-overshoot-day/ https://www.footprintnetwork.org/content/uploads/2019/05/National_Footprint_ Accounts_Guidebook_2019.pdf

Global Footprint Network (2021). National Footprint and Biocapacity Accounts 2021. https://www.footprintnetwork.org/licenses/public-data-package-free/ 
Hervieux, M. S., \& Darné, O. (2013). Environmental Kuznets Curve and ecological footprint: A time series analysis. Economics Bulletin, 35(1), 814-826. http://accessecon.com/Pubs/ EB/2015/Volume35/EB-15-V35-I1-P84.pdf

Kessler, J. J. (1994). Usefulness of the human carrying capacity concept in assessing ecological sustainability of land-use in semi-arid regions. Agriculture, Ecosystems \& Environment, 48(3), 273-284.

Kuznets, S. (1955). Economic growth and income inequality. The American Economic Review, 45(1), 1-28. http://courses.nus.edu.sg/course/ecshua/eca5374/Economics\%20 growth\%20and\%20income\%20inequality_Kuznets_AER55.pdf

Lal, R. (2004). Carbon Sequestration in terrestrial ecosystems. In C. J. Cleveland (ed.), Encyclopedia of Energy (pp. 289-298). Elsevier.

Lee, C. C., \& Chen, M. P. (2021). Ecological footprint, tourism development, and country risk: International evidence. Journal of Cleaner Production, 279, 123671.

Lin, D., Hanscom, L., Martindill, J., Borucke, M., Cohen, L., Galli, A., Lazarus, E., Zokai, G., Iha, K., Eaton, D., \& Wackernagel, M. (2019). Working guidebook to the national footprint and biocapacity accounts. Global Footprint Network. https://www.footprintnetwork.org/ content/uploads/2019/05/National_Footprint_Accounts_Guidebook_2019.pdf

Lotka, A. J. (1925). Elements of Physical Biology. William \& Wilkins Company. https:// archive.org/details/elementsofphysic017171 mbp/page/n1/mode/2up

Lotka, A. J. (1945). The law of evolution as a maximal principle. Human Biology, 17(3), 167-194.

Lovelock, J. (2007). La venganza de la tierra: la teoría de Gaia y el futuro de la humanidad. Planeta.

Mancini, M. S., Galli, A., Niccolucci, V., Lin, D., Hanscom, L., Wackernagel, M., Bastianoni, S., \& Marchettini, N. (2017). Stocks and flows of natural capital: Implications for ecological footprint. Ecological Indicators, 77, 123-128.

McDonough, W., \& Braungart, M. (2005). Cradle to cradle (De la cuna a la cuna). McGraw Hill.

MINCOTUR, Ministerio de Industria, Comercio y Turismo (2019). La balanza comercial agroalimentaria en 2018. Subdirección General de Comercio Internacional de Mercancías. https://comercio.gob.es/ImportacionExportacion/Informes_Estadisticas/Sectores/ Balanza\%20Comercial\%20Agroalimentaria\%20-\%20\%C3\%BAltimo\%20Periodo/ Balanza-Comercial-Agroalimentaria-ultimo-periodo.pdf

MITECO, Ministerio para la Transición Ecológica y el Reto Demográfico. https://sites.google.com/gl.miteco.gob.es/estadisticas/

Naciones Unidas (2018). Las ciudades seguirán creciendo, sobre todo en los países en desarrollo. Noticias ONU. https://www.un.org/development/desa/es/news/population/ 2018-world-urbanization-prospects.html

Odum, H. T. (1973). Energy, Ecology, and Economics. Ambio, 2(6), 220-227.

Odum, H. T. (1996). Environmental accounting: Emergy and decision making. Emergy evaluation. University of Florida.

OECD, Organization for Economic Cooperation and Development (2020). $\mathrm{CO}_{2}$ Emissions Embodied in International Trade and Domestic Final Demand, using the OECD ICIO. https://www.oecd.org/sti/ind/TECO2_OECD_webdoc2020.pdf

Paredis, E., Goeminne, G., Vanhove, W., Maes, F., \& Lambrecht, J. (2009). The concept of ecological debt: its meaning and applicability in international policy. Academia Press. 
Rees, W. E. (1992). Ecological footprints and appropriated carrying capacity: what urban economics leaves out. Environment and urbanization, 4(2), 121-130. https://journals.sagepub.com/doi/abs/10.1177/095624789200400212

Rees, W. E. (1996). Indicadores territoriales de sustentabilidad. Ecología política, 12, 27-41. https://www.jstor.org/stable/20742893

Rees, W. E. (2018, June 06). Climate Change, Globalization and the Uncertain Future of Cities. Public Seminar, Tokio. Co-organised for Institute for Global Environmental Strategies-IGES), United Nations University Institute for the Advanced Study of Sustainability-UNU-IAS).

Rees, W. E., \& Wackernagel, M. (1994). Ecological footprints and appropriated carrying capacity: Measuring the natural capital requirements of the human economy. In A-M. Jansson, M. Hammer, C. Folke, \& R. Costanza (eds.), Investing in natural capital: The ecological economics approach to sustainability (pp. 362-390). Island Press.

Scienceman, D. M. (1987). Energy and emergy. In G. Pillet \& T. Murota (eds.), Environmental Economics: The Analysis of a Major Interface (pp. 257-276). Roland Leimgruber (CFW86-26).

Seto, K. C., Fragkias, M., Güneralp, B., \& Reilly, M. K. (2011). A meta-analysis of global urban land expansion. PLOS ONE, 6(8), e23777.

Stern, D. I. (2004). The rise and fall of the environmental Kuznets curve. World development, 32(8), 1419-1439.

Stiglitz, J. E, Sen, A. K., \& Fitoussi, J.P. (2010). Mismeasuring Our Lives: Why GDP Doesn't Add Up. The New Press.

Uddin, G. A., Salahuddin, M., Alam, K., \& Gow, J. (2017). Ecological footprint and real income: panel data evidence from the 27 highest emitting countries. Ecological Indicators, 77, 166-175.

Ulucak, R., \& Bilgili, F. (2018). A reinvestigation of EKC model by ecological footprint measurement for high, middle and low income countries. Journal of cleaner production, 188, 144-157.

Wackernagel, M., \& Rees, W. (1998). Our ecological footprint: reducing human impact on the earth. The new catalyst bioregional series (Vol. 9). New Society Publishers.

Wackernagel, M., Cranston, G., Morales, J. C., \& Galli, A. (2014). Ecological Footprint Accounts. In G. Atkinson, S. Dietz, E. Neumayer \& M. Agarwala (eds.), Handbook of Sustainable Development (pp. 371-396). Edward Elgar Publishing Limited.

Wackernagel, M., Lin, D., Evans, M., Hanscom, L., \& Raven, P. (2019). Defying the Footprint Oracle: Implications of Country Resource Trends. Sustainability, 11(7), 2164. https://doi.org/10.3390/su11072164

Wang, J., \& Dong, K. (2019). What drives environmental degradation? Evidence from 14 Sub-Saharan African countries. Science of the Total Environment, 656, 165-173.

Wolman, A. (1965). The metabolism of cities. Scientific American, 213(3), 178-193.

Yang, Q., Liu, G., Hao, Y., Coscieme, L., Zhang, J., Jiang, N., Casazza, M., \& Giannetti, B. F. (2018). Quantitative analysis of the dynamic changes of ecological security in the provinces of China through emergy-ecological footprint hybrid indicators. Journal of cleaner production, 184, 678-695.

https://www.sciencedirect.com/science/article/pii/S0959652618306036

York, R., Rosa, E. A., \& Dietz, T. (2004). The ecological footprint intensity of national economies. Journal of Industrial Ecology, 8(4), 139-154. 